\title{
RETENTION AID POLYMER INTERACTIONS WITH CELLULOSIC SURFACES AND SUSPENSIONS: A REVIEW
}

\author{
Martin A. Hubbe, ${ }^{a *}$ Hiroki Nanko, and Michelyn R. McNeal ${ }^{b}$ \\ Retention aids can be defined as very-high-mass, water-soluble \\ polymers that are added to cellulosic fiber slurries before the formation of \\ paper in order to improve the efficiency with which fine particles, \\ including cellulosic fines, are retained in the paper product. Optimization \\ of retention aid performance can be a key to achieving efficient and \\ environmentally responsible papermaking objectives. This article reviews \\ various published theories related to retention aid use. Findings related \\ to three main classes of retention aid polymers are considered: cationic \\ acrylamide copolymers (CPAM), anionic acrylamide copolymers (aPAM), \\ and polyethylene oxide (PEO). While many aspects of the interactions of \\ each of these classes of retention aid products can be understood based \\ on colloid chemistry principles, further research is needed in order to \\ more fully bridge the gap between theory and practice.
}

Keywords: Retention aids; Flocculants; Polyacrylamide; Poly(ethylene oxide); Bridging; Fines; Filler retention

Contact information: a: Department of Forest Biomaterials; NC State University; Campus Box 8005; Raleigh, NC 27695-8005; b: Technical Services; Smurfit-Stone Container Corporation; 1611 CR 85; Stevenson, AL 35772; *Corresponding author: $\underline{\text { ubbe@ncsu.edu }}$

\section{INTRODUCTION}

Papermakers most often use the term "retention aid" when referring to synthetic, water-soluble polyelectrolyte products having molecular mass greater than about 4 million grams per mole. Such polyelectrolytes have been found to be highly effective for the flocculation of various aqueous suspensions, as in the case of wastewater treatment. The present article reviews publications dealing with the interactions of retention aids with cellulosic fibers, fines, and other components of fibrous suspensions as paper is made. Particular emphasis is placed on the topics of adsorption, flocculation, and factors affecting the efficiency of retention of fine particles during the moments preceding the formation of a sheet of paper.

\section{Earlier Reviews}

The subject of adsorption and flocculation by high-mass polyelectrolyte has been addressed in earlier review articles. A number of these publications consider the issue from a broad perspective, not limited to either papermaking or cellulosic materials (Dickinson and Eriksson 1991; Fleer et al. 1993). Other publications are mainly concerned with papermaking applications (McKenzie 1968; Petäjä 1980; Eklund and Lindström 1991; Jaycock and Swales 1994; Horn and Linhart 1996; Swerin and Ödberg 1997; van de Ven 1997; Smith-Palmer and Pelton 2002; Wang 2002; Pelzer 2008). Some 
related review articles also have appeared in this journal, one focused on flocculation of cellulosic fibers (Hubbe 2007), and another focusing on the dewatering of cellulosic fiber suspensions (Hubbe and Heitmann 2007).

\section{Motivations for Use of Retention Aids}

As paper is manufactured, a slurry of fibers and other materials is collected on a continuous screen or between a pair of screens composed of plastic monofilaments. The spaces between the filaments are small enough so that close to $100 \%$ of the cellulosic fibers can be retained during a single pass of the material through the forming operation. However, there also are smaller solid particles, such as parenchyma cells, as well as cellulosic fragments that may have been removed from fiber surfaces during refining operations (Smook 1992). In addition, papermakers employ finely divided mineral particles, i.e. "fillers," in order to achieve favorable appearance properties and, in many cases, to reduce the overall cost of materials. The primary purpose of a retention aid is to increase the efficiency with which these fine materials remain within the paper web as it is being formed.

Even though coagulation of suspensions can be achieved by a broad range of aqueous conditions, including $\mathrm{pH}$ adjustments, aluminum sulfate addition, etc., the hydrodynamic shear levels associated with modern papermaking are sufficient to overcome such treatments (Beghello and Eklund 1999). Estimates of hydrodynamic shear levels in different unit operations of a typical paper machine were given by Tam Doo et al. (1984). Although most modern paper machine systems employ rotating screen "save-alls" to minimize losses of unretained fine matter to wastewater treatment facilities, the most effective strategies to minimize loss of materials from a paper machine system generally include the usage of a retention aid polymer.

\section{Runnability}

Further motivations to use retention aids are related to the efficiency of the papermaking process. The term "runnability" is often used by papermakers to describe the ability to run a paper machine system at a satisfactory rate for long periods of time without interruption. A generally favorable effect of retention aid use on runnability has been attributed to reduced rates of accumulation of deposited material on the wetted surfaces of papermaking equipment. Such deposits, once they have built up to a certain level, may break off and become entrained again into the process flow. Consequences can include unsightly spots in the paper product. In other cases, the entrained material may initiate the formation of a hole in the paper web or cause a break in production.

In a subtle way, retention aids also have the potential to allow increases in the production rate of a paper machine. They can do this by increasing the speed with which water can be removed from the wet web. The mechanisms by which such effects are achieved have been considered in recent reviews (Hubbe and Heitmann 2007; Hubbe et al. 2009). For instance, the retention aids can keep fine matter from clogging up drainage channels within the wet web of paper, or they can help maintain a more porous structure of the sheet as the paper is being formed. In some cases, the rate of dewatering can be the limiting factor affecting the maximum rate of production or the amount of energy that must be expended in drying the paper. 


\section{Efficiency of additives}

Retention aids can play a critical role when used in combination with chemically unstable additives, such as various sizing agents and wet-strength agents (Jaycock and Swales 1994). Even in cases where such additives have a high affinity for cellulosic materials, one can expect that a substantial portion will adsorb onto the fines fraction; hence the retention efficiency of the additives may be far less than $100 \%$. By binding more of the fines to fibers as the paper sheet is being formed, these reactive chemicals become incorporated into paper literally within seconds after their addition to the process, thus ensuring that a maximum of the chemical reactivity remains to "cure" the additive during the process of drying the paper web.

\section{Two-sidedness}

Depending on the design and set-up of the forming equipment, as well as other factors, the paper sheet may have substantial differences between its two sides. Such differences can be expected to be particularly evident when paper is formed on a Fourdrinier machine, in which dewatering occurs mainly in one direction (Smook 1992; Zeilinger and Klein 1995). It has been shown that paper tends to become much more uniform in composition from one side to the other if an effective amount of retention aid polymer has been used (Tanaka et al. 1982). Such issues can be important in grades having tight specifications for appearance. Also, an uneven structure, with respect to the two sides of paper, also can lead to unacceptable curl behavior, particularly in cases where the paper is subject to changes in moisture content or temperature during its use.

\section{Environmental goals}

Finally, retention aids can help the papermaker achieve environmental goals. A study reported by Pelzer (2008) showed that essentially no retention aid remains in liquid effluent from a papermaking facility. While most of the additive becomes part of the paper product, any remaining retention aid polymer becomes incorporated into sludge during wastewater treatment. Energy savings are often observed, since retention aid treatment can promote dewatering. Retention aid products are also, as a rule, non-toxic. The main point to stress, however, is that retention aids reduce the load of solids to be processed in a wastewater treatment plant. Also, the amount of solids that need to be handled by save-all filter systems can be reduced if the retention aid system on a paper machine performs effectively.

\section{Continuing Challenges}

Cost, high shear, high filler, low weight

Costs of retention aid systems need to be justified. First there is the cost of the retention aid polymer itself. But in addition, the benefits need to more than cover the costs associated with transportation, storage, and metering. Several trends in recent years have made the role of retention aid polymers more challenging. There has been a drive toward reducing the basis weights of various paper products. The mineral filler content of many grades of paper has tended to increase with the passage of time. The amount of fresh water being used to produce a given dry mass of paper is decreasing as papermakers strive toward mill closure. Speeds of paper machines generally have increased. Hydro- 
dynamic shear on paper machines tends to increase with increases in the speed of production and the continuing evolution of paper machine design (Tam Doo et al. 1984). Twin-wire forming technology, which is becoming increasingly important, generally yields lower levels of retention efficiency in comparison to traditional one-directional forming and dewatering technology (Sivén and Manner 2001). All of these trends have increased the demands on retention aid systems.

\section{Retention of both fiber fines and fillers}

Fillers, in particular, place high demands on retention aids. Not only are filler particles much too small to be directly retained by the typical forming fabrics used on paper machines, but also the specific surface areas are relatively high, e.g. $5-15 \mathrm{~m}^{2} / \mathrm{g}$. The dosage of a retention aid that is required to achieve a set level of retention efficiency generally can be expected to increase with increasing specific surface area of the solids in the fiber suspension. Uncoated printing paper grades often have filler levels in the range of 10 to 30 percent, based on product mass (see Bøhmer 1981; Hubbe 2004). Furthermore, if retention aids are applied carelessly, causing filler to become self-agglomerated, the ability of the mineral particles to scatter light can be reduced (Gill 1993).

\section{Dissolved and colloidal substances}

As will be discussed later in more detail, the performance of certain retention aid systems can be significantly impaired by the presence of various materials commonly present at different levels in the process waters of paper machine systems. In particular, negatively charged dissolved polymeric and colloidal substances (DCS) are known to form complexes with cationic polymers, neutralizing their charge and rendering them ineffective as flocculants (Pelton et al. 1980; Wågberg and Aselli 1995; Swerin and Ödberg 1997; Nässman et al. 1998; Allen et al. 1999; Dunham et al. 2000, 2002; Holmbom and Sundberg 2003; Nurmi et al. 2003). The concentrations of DCS and salts can increase dramatically with increases in the re-use of process water (Pietschker et al. 1993; Polverari et al. 2001).

\section{Drainage and formation uniformity}

The paper quality attribute that is most likely to be adversely affected by the use of retention aids, especially at high levels of addition, is the uniformity within a length scale of about 2 to $10 \mathrm{~mm}$, i.e. the "formation uniformity." Not only does the presence of fiber flocs within paper tend to make its appearance less uniform, but a flocculated sheet also does not generally respond well to vacuum dewatering (Britt and Unbehend 1985; Räisänen et al. 1994). Rather than uniformly compressing and pulling water from the paper, air will tend to be sucked through the thin areas adjacent to fiber flocs, increasing the amount of pumping required in order to sustain a prescribed level of vacuum. Strong interrelationships between retention, drainage, flocculation, and reduced strength have been observed (Jokinen and Palonen 1986; Horn and Linhart 1996).

\section{Mixing}

Recent research suggests that more efficient and uniform performance of retention aid products can be achieved by means of better mixing of the polymer with the fiber 
slurry (Lamminen et al. 2005). Various factors combine to make the problem of mixing retention aid solution with fiber slurries particularly challenging. These factors include the viscous nature of retention aid products, the tendency of fibers in suspensions to suppress turbulent mixing, the tendency of cellulosic fibers to form flocs, and the constraints imposed by the designs of various paper forming machines. Fluid dynamic simulations have suggested that better results can be achieved with various mixing devices and dilution of the retention aid (Stratton and Miller 1993; Lamminen et al. 2005; Matula 2006).

\section{Imaging}

A further challenge in the study of retention aid behavior lies in the very small scale at which the critical events take place. For instance, conventional microscopy is inadequate to show what happens at the interface between a retention aid molecule and a cellulosic surface. However, recent advances in nanotechnology now offer hope for better understanding of retention aid systems. For instance, transmission electron microscopy has been applied for the first time recently to reveal the appearance of retention aid molecules during their interaction with cellulosic fines (Nanko and Pan 2003; McNeal et al. 2005; Nanko et al. 2006).

\section{Classification of Retention Aid Systems}

Retention aid systems are often categorized according to the charged nature of the high-mass polymer. This approach can be justified because, as will be shown, the ionic charge of a polyelectrolyte can be expected to play a major role in how it behaves. Thus, major sections of this review article will be devoted, respectively, to cationic, anionic, and nonionic retention aid polymer additives. However, to begin the discussion, the following section will consider some theoretical concepts that are likely to be important irrespective of which retention aid polymer is being used.

To provide some context for the discussion to follow, a few comments can be made regarding the manner in which retention aids typically are added to the suspension of cellulosic fibers and other materials before a paper sheet is formed. Retention aids are usually highly diluted with water before their introduction to the fiber suspension. A solids content of $0.2 \%$ or even less at the point of addition helps to ensure effective distribution of the additive. Typical dosages are in the range of $0.01 \%$ to $0.4 \%$, based on active polymer addition to furnish solids. Though papermakers sometimes add retention aid polymers as early a fan pump, which is used to dilute the incoming stock from about $4 \%$ to $6 \%$ solids down to about $0.4 \%$ to $1 \%$ solids (Smook 1992 ), it is more common to add the polymer solution very late in the process, either just before or just after the stock passes through a final screening operation.

\section{THEORETICAL ASPECTS OF RETENTION AID USE}

Regardless of their detailed structure and charge characteristics, it is reasonable to expect certain common behaviors to follow as a consequence of (a) the very high molecular mass, (b) the generally linear macromolecular structure, and (c) the water- 
soluble nature of the retention aid polymers that are used commonly in papermaking. If one assumes a molecular mass of 10 million grams per mole and an average repeat unit mass of 100 grams per mole, it can be estimated that a typical retention aid polymer has roughly 100,000 monomer units. If each such unit were represented by a $1 \mathrm{~mm}$ bead, i.e. roughly the diameter of angel-hair spaghetti, then the length of the chain can be calculated as 100 meters. One can well imagine that a fine strand of noodle having the length equivalent to a ball field might be subject to breakage. To carry the noodle analogy one step further, the flexible nature of a retention aid polymer might be better represented by the example of a cooked noodle. Thus it is also reasonable to be concerned with the coiled nature of retention aid polymers, the effects of stirring (agitation) on their conformation, and the likelihood of entanglements.

\section{Solution Conformation of High-Mass Polyelectrolytes}

The subject of dissolved polymer conformations is covered well in other texts (Eisenberg 1976; Fleer et al. 1993; Jönsson et al. 1998). It has been proposed that a large effective size of a polyelectrolyte is a key determinant governing the effectiveness of polymeric flocculating agents (Somadundaran et al. 1992). It is well known that the charged groups along the chain of a polyelectrolyte give rise to a more expanded molecular conformation (Beer et al. 1997; Ariel and Andelman 2003). The effective size of a polyelectrolyte is expected to increase with increasing charge density, but such expansion will tend to be suppressed in the presence of increasing concentrations of monomeric ions.

Allowing for relatively free rotation about the $-\mathrm{C}-\mathrm{C}-$ and $-\mathrm{C}-\mathrm{O}-$ covalent bonds in a macromolecular chain, it is reasonable to expect water-soluble polymers of high molecular mass to adopt a random coil conformation. Though, in theory, such a polymer might happen at one instant to be completely stretched out, thermodynamics dictates that such events would be exceedingly rare. By contrast, there is considerable evidence that certain kinds of dissolved polymers can adopt helical conformations; such behavior can be favored by a macromolecule's preferred rotational conformations about covalent bonds and by steric or electrostatic interactions among adjacent pendent groups on the chain. For instance polyethylene oxide has a tendency to adopt a helical conformation (Yoshihara et al. 1964; Kobayashi and Sato 2008). It is not clear whether helical conformations can be expected under typical aqueous conditions (Bedrov and Smith 2003). Recent work showed that the conformation of PEO chains in solution also can be influenced by the flow environment (Perkins et al. 1997; Duval and Boue 2007).

\section{Polyelectrolyte Adsorption}

The subject of polyelectrolyte adsorption has been extensively reviewed (van de Steeg et al. 1992; Fleer et al. 1993; Ödberg et al. 1993; Swerin and Ödberg 1997; Wågberg 2000; Smith-Palmer and Pelton 2002; Claesson et al. 2005). On the one hand, it can be useful to envision the adsorption interactions as taking place at a dividing plane between an aqueous phase and a cellulosic phase. However, as noted by Pelton (1993), the location of that plane may be very hard to define adjacent to fibrillated cellulosic fibers, due to their complex structure. Cellulosic surfaces are often covered with nanowidth cellulosic hair-like features, in addition to water-swollen hemicellulose and other 
associated colloidal matter. Thus, it is useful to view interactions of retention aids with cellulosic surfaces as a form of polyelectrolyte complexation, taking place with a threedimensional surface region. The subtle interactions are highlighted by the fact that polyelectrolyte adsorption can influence how much water is held on and within cellulosic fibers, as in the case of a centrifugal dewatering test (Swerin et al. 1990; Ström and Kunnas 1991).

In the case of retention aid polymers, due to their high molecular mass, typically 5 to 20 million grams per mole, certain aspects of polyelectrolyte adsorption tend to be more pronounced, compared to adsorption of other solutes. In particular, due to the possibility of attachment at a great number of points simultaneously, adsorption of retention aids onto solid substrates tends to be irreversible (Smith-Palmer and Pelton 2002; Wågberg et al. 1988). Another consequence of very long chain length is that molecular conformational changes accompanying adsorption are often slow relative to the time scales associated with many of their applications in papermaking (Lindström and Söremark 1976; Wågberg et al. 1988; Ödberg et al. 1993; Swerin and Ödberg 1997; Wågberg and Nygren 1999; Shulga et al. 2003a,b).

In the case of relatively low mass, high charge density polyelectrolytes, it is often useful to assume that the amount of adsorption, at equilibrium, should be controlled by a charge neutralization interaction (Winter et al. 1986). Indeed, Strazdins (1974) observed a linear relationship between the adsorption of poly-diallyldimethylammonium chloride and the hydrodynamic surface area of papermaking pulp that had been refined for different lengths of time.

A particularly sensitive way to study the mechanisms involved in polyelectrolyte adsorption involves sequential addition of polymeric agents to a papermaking suspension. Thus, Tanaka et al. (1999) evaluated the competitive adsorption of different cationic retention aid molecules having different charge densities. Although the adsorbed amounts were clearly related to the amount of negative charge present on the cellulosic surfaces, absorption always exceeded what would have been predicted based on a 1:1 stoichiometric interaction between charged groups. Whichever polyelectrolyte was added first tended to "hog" the available adsorption sites, lending weight to the term "irreversible adsorption," at least within a time scale of minutes.

\section{Collision Frequency Factors}

If one starts with the concept of high-affinity, essentially irreversible interactions between retention aid polymers and cellulosic surfaces, one of the implications is that the initial contacts between such polymers and different surfaces ought to make a critical difference. For instance, if the initial collisions between the polyelectrolytes take place with cellulosic fines, then it would be reasonable to expect a high proportion of the added polymer to remain attached to such surfaces during succeeding steps in a process.

As has been set forth in a series of articles, collisions among polyelectrolytes, fibers, cellulosic fines, mineral particles, and other components of a typical papermaking suspension tend to be brought about by two kinds of processes (Adachi 1995; Alince 1996; Swerin et al. 1996; Swerin and Ödberg 1997; Hogg 1999). On the one hand, even in unstirred solutions, the suspended particles undergo continual, random "Brownian" motion, due to the thermal energy and collisions among molecules in the fluid and 
various suspended matter. On the other hand, collisions among various suspended materials can be brought about by flow or turbulence. As will be described below, the flow-induced (orthokinetic) collisions tend to be more important than the thermal (perikinetic) collisions in most situations involving retention aid polymers.

\section{Thermally induced (perikinetic) collisions}

In systems with a defined temperature, each object on average possesses a certain amount of translational kinetic energy. Here the term "object" is used in a very broad sense, since the concepts apply to molecules, ions, colloidal particles, and even to macroscopic objects. The average energy associated with the thermal motion of each object within each of the three Cartesian coordinates is given by the following definition,

$$
E_{k}=1 / 2 k T
$$

where $k$ is the Boltzmann constant, and $T$ is the absolute temperature.

The term "Brownian motion" is often used to describe the thermal motions of objects that are large enough to be seen through a microscope. Indeed, it is relatively easy to observe Brownian motion of fine particles in aqueous samples from a papermaking facility by viewing a drop of process water with a conventional microscope.

Equation (1) has some important implications from the standpoint of collisions between different sized objects in a suspension. First, the kinetic energy, and hence the average velocity of a given particle in suspension, will tend to increase in proportion to the absolute temperature. Second, the average velocity will increase with decreasing size of the object. Thus it is reasonable to expect that thermal (Brownian) diffusion processes may be the most important factor in bringing about collisions that involve the smallest objects, i.e. individual ions and molecules in a suspension.

Researchers have considered the rates of inter-particle collisions in systems with different concentrations and sizes of objects at different temperatures and fluid viscosities, with and without the action of inter-particle forces (Verwey and Overbeek 1948; Hogg et al. 1966; Adachi 1995). For instance if one is interested in collisions between objects having radius values of $R_{1}$ and $R_{2}$, respectively, the frequency that the particles strike each other will be proportional to the factor $\left(R_{1}+R_{2}\right)^{2} /\left(R_{1} R_{2}\right)$. One of the consequences of this relationship is that Brownian collisions are strongly favored between objects of differing size. This makes sense, since the smaller objects diffuse relatively rapidly and the larger objects provide easy-to-hit targets.

\section{Flow-induced (orthokinetic) collisions}

Compared to Brownian motion by itself, agitation of a suspension tends to promote more frequent collisions among the suspended objects (Alince 1996; Swerin and Ödberg 1997; Hogg 1999). Rates of collision are expected to increase strongly with increasing size of suspended objects and with increasing rates of hydrodynamic shear. Collision frequencies are proportional to the term $\left(R_{1}+R_{2}\right)^{3}$. As noted in the cited works, orthokinetic collisions are expected to be many orders of magnitude more frequent than perikinetic collisions in the case of relatively large objects such as retention aid molecules, cellulosic fines, fibers, etc., at levels of agitation that are characteristic of 
papermaking systems. As noted by Hogg (1999), this effect can be expected to result in a disproportionate amount of initial deposition of retention aid molecules onto cellulosic fibers, in comparison to the amount that deposits on an equivalent surface area of much smaller objects. The latter might include objects such as titanium dioxide particles, droplets of emulsified hydrophobic sizing agent, etc.

A number of factors tend to work together so that collisions between retention aid molecules and cellulosic fibers in an agitated suspension are even more frequent compared to the rates calculated according to equations given in the articles just cited. Both the cellulosic fibers and the polymers have a highly elongated nature, whereas the equations typically are derived for spherical objects. Furthermore, the fibers typically have been refined, such that fine, cellulosic fibrils protrude outward into the surrounding solution, greatly increasing the opportunity to intercept relatively long macromolecules present in the suspending fluid, especially in cases where the fluid is in motion relative to the fiber. That relative motion can be amplified in cases where fibers become flocculated into bunches, such that there is an amplification of hydrodynamic shear stress at the outer edges of fiber flocs.

Flow-induced processes tend to favor collisions among like-size particles (van de Ven 1981). To a first approximation it is possible to predict the trajectories of particles passing through a packed bed based on the unperturbed streamlines of flow. However, such calculations tend to over-estimate rates of inter-particle collisions due to a lubrication effect. That is, as surfaces start to approach each other closely, there is a sharply increasing resistance to closer approach due to the viscosity of intervening fluid (Brenner 1968). The hydrodynamic avoidance effect, as just described, tends to be most consequential in the case of unequal-sized objects, such as a cellulosic fiber and a tiny particle of titanium dioxide, etc. (van de Ven 1981). This effect suggests that it is more likely for a retention aid molecule to collide with, and become attached to a small fibril extending from a cellulosic fiber, rather than to collide with the main body of the fiber itself. A complete analysis also has to take into account Brownian motion, in addition to surface forces and hydrodynamic effects (Adamczyk and van de Ven 1981).

\section{Attachments before vs. during mat formation}

The insightful work of Britt and Unbehend (Britt 1973a,b; Britt and Unbehend 1976a) showed quite clearly that retention aids can promote attachments between fine particles and cellulosic fibers. Although some doubt was raised by Davison (1983), most investigators attribute the beneficial effects of retention aids to the establishment of such fine-particle-to-cellulose fiber attachments. Davison proposed, on the contrary, that a main pathway to retention of fine particles, including mineral fillers added to paper, was due to self-agglomeration of fine matter. It was proposed that such agglomerated material becomes large enough to be efficiently filtered by the fiber mat. In practice, Davison's mechanism tends to converge with that of Britt and Unbehend in cases where agglomeration can involve cellulosic fines, which often can be sieved by the fibers in the wet web as paper is being formed.

A critical question remains, however. That is, when are the contacts between the retained fine particles established? On the one hand, it can be argued that if the attachments are established shortly after the addition of a retention aid polymer, say in 
the approach flow before the intake manifold of a headbox, then there is a possibility that hydrodynamic forces could dislodge those particles from fiber surfaces. On the other hand, it is possible that some fine particles deposit onto fiber surfaces during the formation of the sheet. Results of experiments carried out by Solberg and Wågberg (2002) suggest that attachment of filler particles to fiber surfaces during the actual dewatering of a paper web occurs with too low a probability to make a significant contribution to retention. These investigators considered a variety of fiber pads, including situations with high mass per unit area. In addition, they considered cases with laminar flow, which was argued to offer a best-case scenario for fine-particle interception by the fiber mat during the dewatering of paper. It was concluded that most of the deposition must occur prior to mat formation. A similar conclusion was earlier proposed by van de Ven (1984), based on theoretical considerations. Trajectory analysis indicated that during the actual formation of paper most of the unattached fine particles can be expected to follow streamlines that do not come close enough to fiber surfaces to permit establishment of strong forces of attraction between the respective surfaces.

\section{Rates of conformational change}

For reasons to be described, the conformation of adsorbed macromolecules can be expected to affect interactions between the surfaces in agitated suspensions of cellulosic material. An example of this is provided by Somasundaran et al. (1992), who showed that a more extended adsorbed conformation of a high-molecular mass polyelectrolyte tended to promote greater flocculation in the case of alumina suspensions. Presumably if tails or loops of polyelectrolyte extend outwards from a suspended particle, the collision cross-section of that object is increased, i.e. it acts like a bigger target for other particles to hit. However, polymer conformations can be expected to change with the passage of time and during exposure to hydrodynamic shear (Adachi 1995). The importance of this issue is highlighted by the work of Forsberg and Ström (1994), who found that maximum retention was obtained if paper was formed approximately 10 to 20 seconds after addition of retention aid polymers.

Wågberg et al. (1988) discuss several studies dealing with the influence of time on adsorbed conformations of retention aids and related polyelectrolytes. Based on rates of release of counter-ions from specially prepared cellulosic surfaces, they concluded that although poly-DADMAC, a highly charged cationic polymer, initially adsorbed very rapidly on fiber surfaces, there was a much slower process of reconformation. Petlicki and van de Ven (1994) showed that the adsorption of polyethyleneimine depended also on rates of diffusion through pit openings, giving access to the lumen spaces in the interior of pulp fibers.

Recent evidence suggests that retention aid polymers attached to cellulosic surfaces can become stretched out as a consequence of flow past the surface (Nanko and Pan 2003; McNeal et al. 2005; Nanko et al. 2006). Transmission electron micrographs, shown in Fig. 1, come from the cited studies. In this work negatively charged gold nanoparticles were used to more clearly show the location of the chains or strands of positively charged retention aid molecules. What is particularly notable in Fig. 1A, which was obtained in the absence of salt, is the stretched, almost linear shape of the macromolecular material extending from the fibril surface. The stretched nature and also 
the relatively uniform direction of the extended chains are tentatively attributed to the presence of flow as the solids were collected onto loops of wire and transferred to TEM colloform film supports. Part B of Fig. 1 shows a much more collapsed conformation of the polyelectrolytes in the case of a high-density cationic acrylamide copolymer. The more condensed conformation is consistent with a stronger interaction between the opposite charges of the dissolved polymer and the substrate.
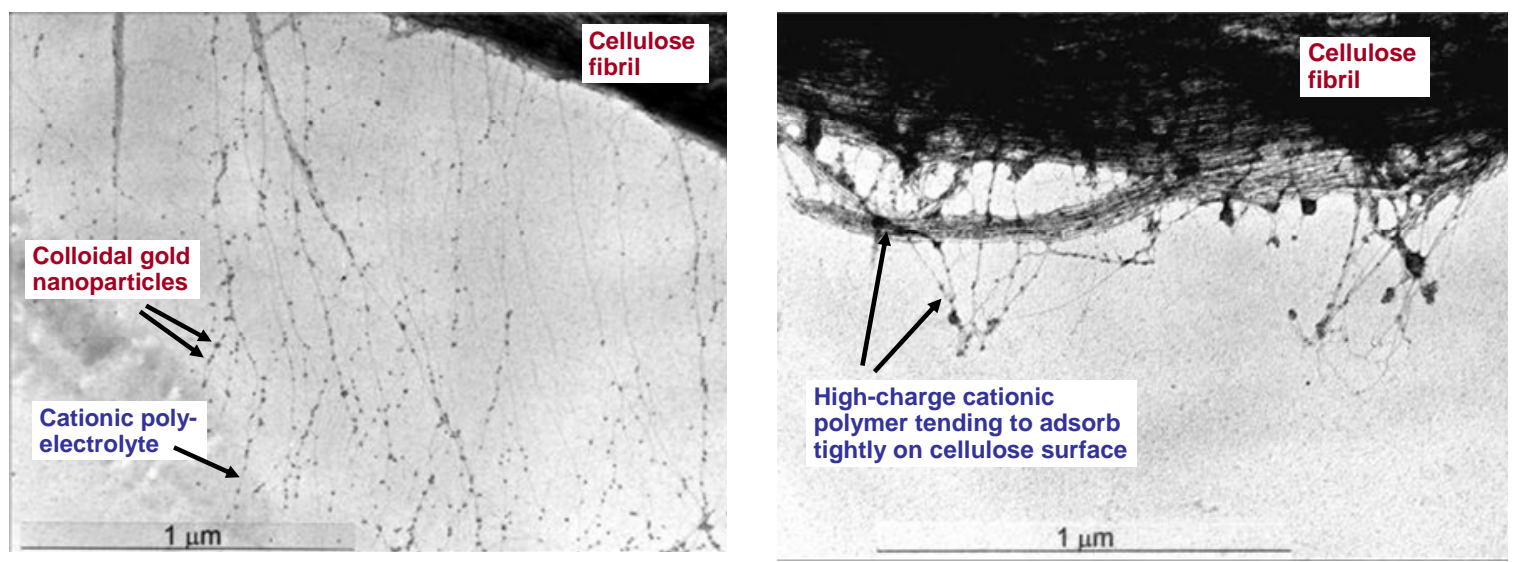

Fig. 1. Transmission electron micrograph (TEM) images of cationic acrylamide copolymer molecules attached to a cellulosic fibril. A: High molecular-mass, low-charge density cPAM in the absence of salt, following collection on a wire loop and transfer to a thin film; B: High charge density CPAM (of similar molecular mass).

Figures 2, parts $\mathrm{A}$ and $\mathrm{B}$, provide cartoon illustrations suggesting how flow can first stretch out the adsorbed polymer chains, then, due to the influence of turbulent eddies, cause the formation of multi-chain strands.
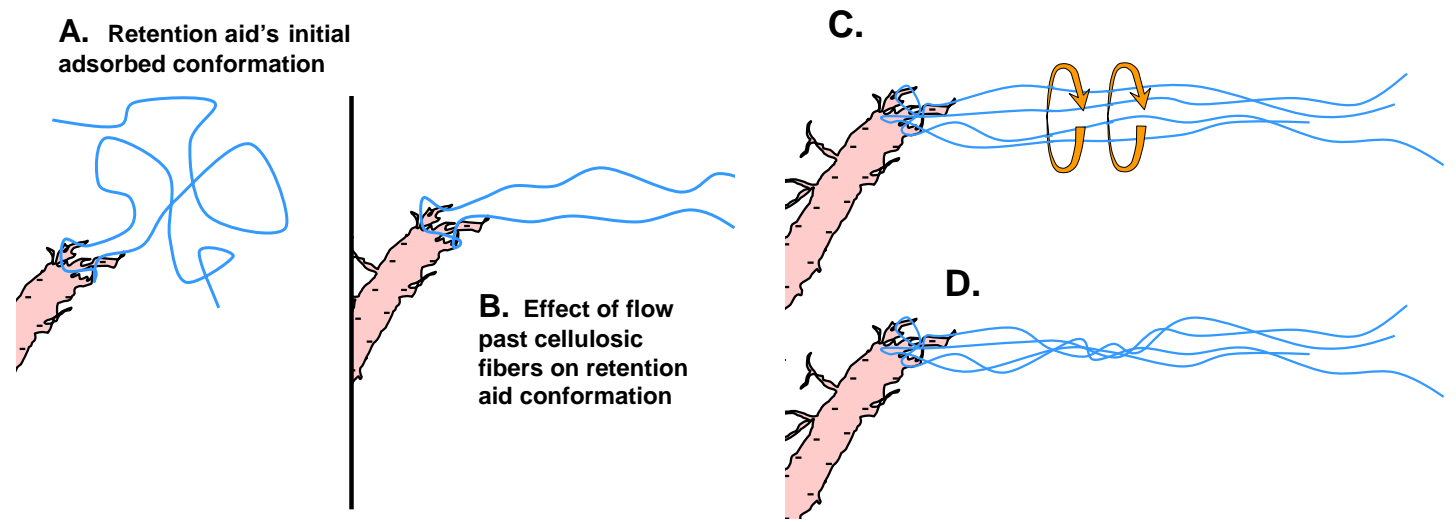

Fig. 2. Effects of flow on the conformation of a retention aid polymer partly attached to a cellulosic fibril. A: Presumed initial adsorbed conformation. B: Tails of polyelectrolyte stretched out in the prevailing direction of flow past the point of attachment. C: Local eddies of flow that may occur due to turbulence. D: Local twisting, resulting in multi-chain strands of retention aid. Color coding: Pink = negative net charge (e.g. fibers); Blue = positive net charge (e.g. a cationic retention aid). 
The recent findings cast some doubt on a commonly expressed assumption that the adsorbed conformation, especially during the initial moments of attachment, usually ought to have a somewhat round shape, as would be expected for a dissolved polymer undergoing random motions. In addition, transmission electron micrographs showed evidence of strand formation, presumably resulting from the localized twisting among groups of retention aid polymer chains. As illustrated in parts $\mathrm{C}$ and $\mathrm{D}$ of the figure, twisted strands are expected to come about due to the action of localized eddies of flow.

\section{Flocculation}

The broad subject of the flocculation of cellulosic fiber suspensions was considered in an earlier review article, which also considered fiber flocculation in the absence of polyelectrolytes (Hubbe 2007). The focus of the present article is limited to a narrower meaning of the word "flocculation," mainly focusing on the local interactions between wetted surfaces of solids in a suspension, and how these interactions can be affected by the presence of high-mass polyelectrolytes.

Three idealized descriptions of how retention aid polymers can affect attachment between solid surfaces in cellulosic suspensions will be considered: "charged patch", "charge neutralization", and "bridging" (see, especially Petäjä 1980; Stratton 1983). In the following descriptions, the particle surfaces (cellulosic materials and fillers) are assumed to be negatively charged, and the polyelectrolytes are assumed to be cationic. According to the charged patch mechanism, one envisions that the polyelectrolyte adsorbs first onto the surface of one particle, and that there is sufficient time such that the polyelectrolyte can lie down and get a firm grip onto that surface before it collides with a second particle's surface. Areas that are covered by patches of cationic polymer would be expected to attract and bind to uncovered areas on the colliding particle's surface. According to "charge neutralization," one envisions a less localized adsorption, possibly due to the size of molecules or the speed with which they distribute themselves evenly over the surfaces. Charge neutralization also can be expected if the system is treated with a suitable concentration of multi-valent ions, as in the case of aluminum sulfate (papermaker's alum) treatment. Finally, according to a "bridging" mechanism one envisions a process in which the adsorbed polyelectrolyte does not lie flat on the surface, but extends outward from one or more anchor points on the surface. Tails and loops of the polymer extend outward from the first surface upon which the polymer is adsorbed, and they comes into contact with a second surface, thus forming a bridge between the two particles. Pictorial representations of the three mechanisms are given in Fig. 3.

\section{Charged patch mechanism}

The charged patch mechanism of flocculation is believed to play a key role in many papermaking applications (Kasper 1971; Goossens and Luner 1976; Dickinson and Eriksson 1991; Horn and Linhart 1996; Tripattharanan et al. 2004b). Evidence that tends to favor a charged patch mechanism, rather than just neutralization of charges (see next) includes the fact that addition of highly charged cationic polymers to a fiber suspension often achieves stronger flocculation that can be achieved just by salt addition. Floc strength tends to increase with increasing molecular mass of such additives (Alince and Robertson 1974; Gruber et al. 1996a,b). 

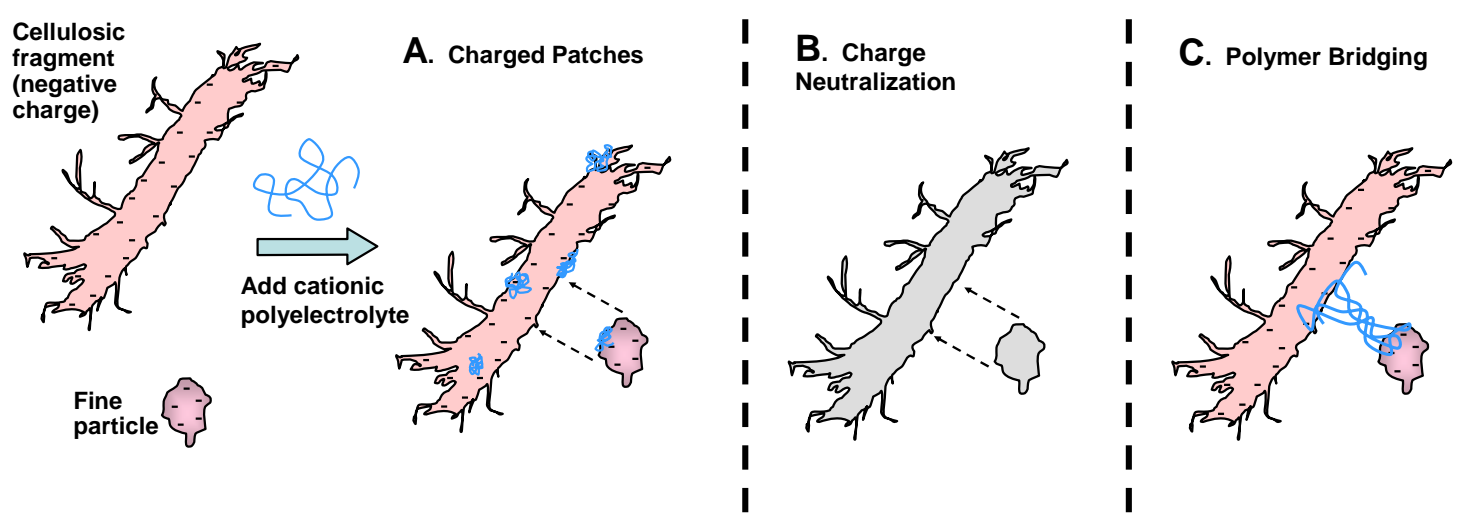

Fig. 3. Sketches representing three idealized mechanisms by which polyelectrolytes might be expected to increase agglomeration in aqueous suspensions. A: Charged patches; B: Charge neutralization; C: Polymer bridging; Color code: Red/pink = negative charge; Blue = positive charge; Gray = neutral charge

Attraction between a large cationic patch on one surface with a large uncovered area on an adjacent surface is more likely to be effective, compared to attraction between small areas of contrasting charge. Although it might be possible, in principle, to achieve strong close-range attraction in the case of "mosaics" of charge on adjacent particles (Sandell and Luner 1974), such effects would not be expected to be as effective in exerting a net attractive force during the initial approach of the surfaces. One of the reasons for this is that the random Brownian motion of tiny particles includes spinning motions. Such motions would tend to average out some of the localized charge characteristics of such particles, especially when the surfaces are relatively far apart from each other.

There are various reasons to expect that the charged patch mechanism can play an important role in papermaking. Imaging studies with atomic force microscopy have shown patch-like shapes of individual highly cationic polyethyleneimine (PEI) molecules adsorbed onto a smooth, negatively charged substrate (Pfau et al. 1999; Horn 2001). Also, the charged patch mechanism is consistent with the results of studies in which just one set of surfaces was treated with cationic polyelectrolyte, and then the treated surfaces were allowed to contact a second set of surfaces (Das and Lomas 1973; Kamiti and van de Ven 1995). Such studies reveal that attraction between uncovered surfaces and surfaces treated with a cationic polyelectrolyte, even one of low to moderate mass, can be much stronger than what can be achieved in the absence of polyelectrolytes. Electrophoretic mobility measurements often show a wide distribution of electrical charge characterisitics for the fine particles in papermaking process water, as would be expected to result from non-uniform, patch-like adsorption of macromolecules (Sanders and Schaefer 1994). Finally, it has often been observed that maximum flocculation, or a maximum in the attractive forces between surfaces, is achieved when just enough polyelectrolyte, opposite in charge to the substrate, has been added to partially cover the surfaces (Kasper 1971; Gregory 1973; Gruber et al. 1996b; Österberg 2000; SmithPalmer and Pelton 2002). 


\section{Charge neutralization and zeta potential}

In principle, if just enough oppositely charged polyelectrolyte adsorbs onto a surface to neutralize the net charge, then mutual attraction and agglomeration can be expected to occur (Verwey and Overbeek 1948). Dispersion forces, a component of the forces discovered by van der Waals (London 1930), are mainly responsible for this effect. While it is tempting to dismiss dispersion forces as probably being too weak to contribute to the performance of retention aid polymers, it is worth keeping in mind that dispersion forces are mostly responsible for holding together the linear polyethylene macromolecules in plastic bottles and similar products.

There is much evidence in support of charge neutralization, as a contributing mechanism for retention of fine particles during papermaking. In particular, various studies have shown instances of maximum retention when the zeta potential, an indication of surface charge, was near to zero (Chang and Robertson 1967; Arno et al. 1974; Lindström et al. 1974; Sandell and Luner 1974; Strazdins 1974; Horn and Melzer 1975, 1977; Gruber et al. 1996b; Bhardwaj et al. 2005; Horn and Linhart 1996; Solberg and Wågberg 2003a; Hubbe et al. 2007a; Salmi et al. 2007a). The cited studies mainly were concerned with the effects of highly charged cationic additives having low to moderate molecular mass.

It has been observed, however, that the neutralization principle, as just described, does not seem to apply well in systems where very-high-mass polyelectrolytes, i.e. retention aids, are being used. In such systems there was no agreement between the polymer dosage sufficient to yield a zero zeta potential and the dosage needed to bring about a maximum in retention efficiency (Britt 1973b; Horn and Melzer 1977; Horn and Linhart 1996). Even in the case of high-charge-density cationic polymers, some investigations showed broad maxima in the plots of retention efficiency versus polymer dosage (Sandell and Luner 1974). Such results are consistent with a degree of irreversibility in the flocculation mechanism. In addition, a charge neutralization mechanism by itself cannot explain why the performance of retention aid polymers tends to be a very strong function of molecular mass (Lindström et al. 1974; 1976).

\section{Bridging}

When discussing the behavior of high-mass polyelectrolytes, the term "bridging" can be defined as a mechanism in which extended chains of polyelectrolyte achieve a bonding connection between adjacent surfaces in aqueous suspension. In contrast to the charged patch mechanism already discussed, the polyelectrolytes involved in bridging have not adopted a flat adsorbed conformation onto cellulosic surfaces, either due to insufficient time or for other reasons that will be discussed.

The concept of bridging was first proposed in order to account for flocculation effects even in cases where there was a net electrostatic repulsion between suspended particles (Ruehrwein and Ward 1952; La Mer and Healy 1963). It was noted that effective flocculants in such situations were polyelectrolytes having sufficient chain length in order to extend beyond the range of the strong repulsive forces between the particles. This situation is illustrated in Fig. 4. Indeed, as already mentioned, the effectiveness of retention aids typically increases with molecular mass, at least up the range of 5 million grams per mole (Fleer and Lyklema 1974; Lindström et al. 1976). The 
tendency toward irreversible flocculation, in the case of high-mass polyelectrolytes, was noticed already by Ruehrwein and Ward (1952).

A.

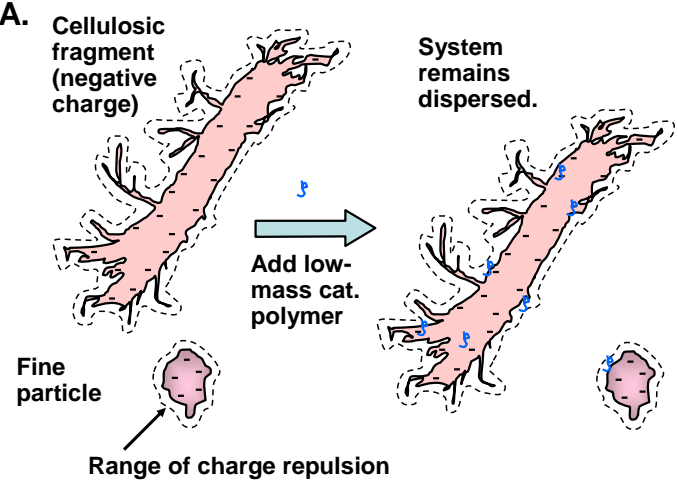

B.

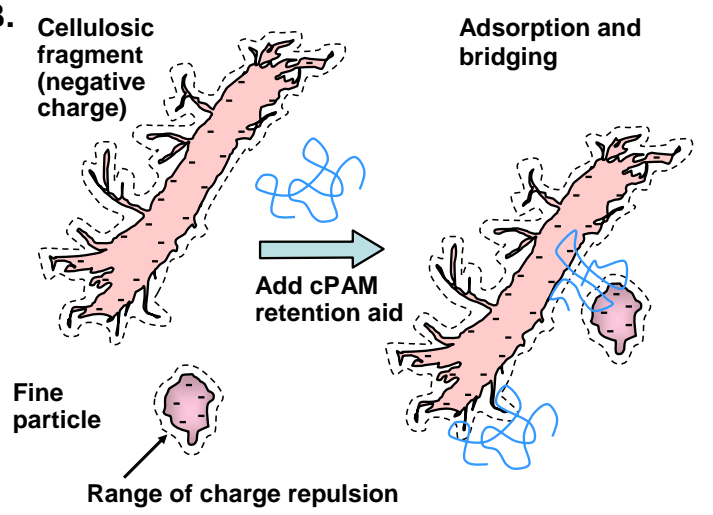

Fig. 4. Concept of polymer bridging, in the case of net-negative cellulosic surfaces and cationic polyelectrolytes. A: Low-molecular-mass polymer does not cause bridging flocculation, since its adsorbed conformation does not extend beyond the range of strong electrostatic forces of repulsion between the surfaces; B: High-mass polymer remains in an extended conformation long enough to allow attachment to two surfaces, even in the presence of net repulsive electrostatic forces between the surfaces.

While the bridging mechanism has been explained in cartoon form for many years, e.g. Fig. 4B, it is only recently that such effects have been observed by nano-scale imaging (see Nanko and Pan 2003; McNeal et al. 2005). Figure 5 shows a couple of images that were obtained in the course of the cited work.

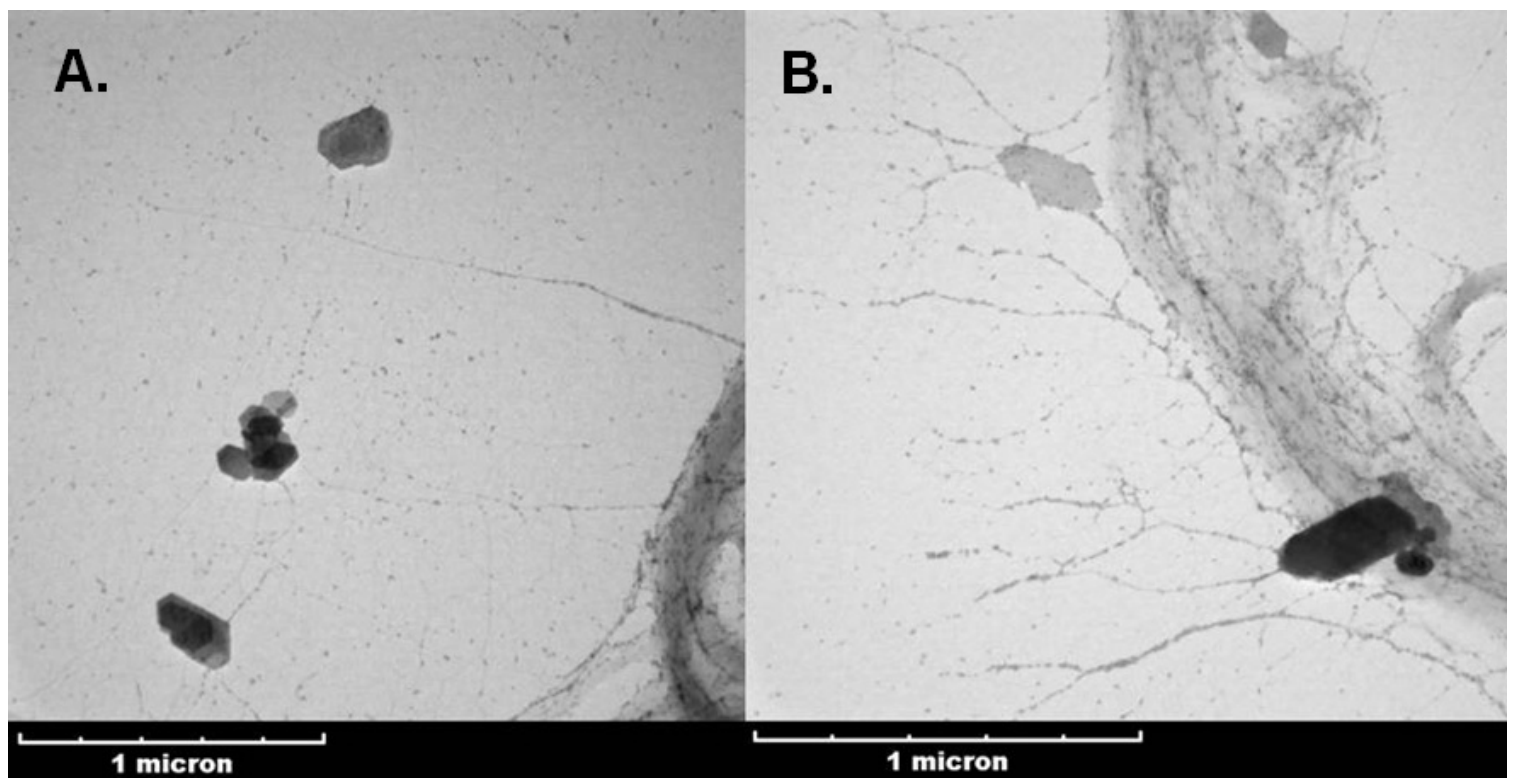

Fig. 5. Transmission electron micrographs showing cationic polyacrylamide bridges formed between cellulose fibrils and filler clay (kaolinite) particles. A: clay particles bound by long polymer bridges; B: clay particles held close to cellulosic fibril by polymer bridges 
As shown, it is possible for such bridges, composed of chains or strands of macromolecules, to extend for more than a micrometer. The polygonal shapes appearing in the figure are images of kaolinite clay. Because the positively charged polymer interacts strongly with negatively charged clay surfaces, any clay particles coming close to the fiber are likely to get stuck. As suggested by part B of the figure, it is reasonable to expect the polymer bridges to become more matted down onto the fiber surfaces in the presence of chaotic flow events and with the passage of time.

Another characteristic feature of bridging is that the rate of flocculation is expected to be maximized when the degree of coverage of the surfaces is far below the level of polyelectrolytes required to saturate the surface. Gregory (1973) derived relationships between flocculation rate and degree of coverage. These concepts appear to be valid from the polymer bridging mechanism as well as the charged patch mechanism. However, because his cationic polyacrylamide samples were lower in mass in comparison to typical retention aid polymers (e.g. no more than $100,000 \mathrm{~g} / \mathrm{mole}$ ), the charged patch mechanism may be the most correct term to use in describing Gregory's findings.

\section{Rates of flocculation}

Further evidence of a bridging mechanism has been obtained in studies of rates of flocculation. Pelssers et al. (1990) observed strong flocculation of suspensions to which flocculant molecules had been freshly added, such that it was reasonable to assume that tails and loops of polyelectrolyte still extended far out from the surfaces of the suspended particles. By contrast, much of the flocculating ability was lost with the passage of time, presumably because of the gradual reorganizing of the polymer coils, and perhaps partly due to breakage or redistribution as a consequence of time and hydrodynamic shear.

Walles (1968) obtained early evidence that very-high-mass retention aid polymers could increase the rate of collisions among agitated particles, thus achieving rates of agglomeration much higher than those obtained just by removing electrostatic repulsive forces. The effect was attributed to dangling tails or loops of polyelectrolyte extending outwards from the surfaces of suspended particles. Such tails and loops can be expected to increase the collision cross-section of suspended particles.

\section{Non-equilibrium, trapped states}

The term "trapped non-equilibrium states" has been used to describe certain interactions of very-high-mass polyelectrolytes (Claesson et al. 2005). It was noted that the molecular conformations in a flocculated suspension, after treatment with a high-mass polyelectrolyte, cannot be predicted from the bulk concentrations. Rather, they depend on the system's history of mixing, addition sequences, and time intervals, etc. Such behavior can be expected in cases where the interactions between the polyelectrolytes and substrates are strong, occurring almost simultaneously at numerous points along a macromolecular chain, such that subsequent approach to a true equilibrium conformation does not occur to a significant extent within a reasonable time of observation.

Examples of non-equilibrium behavior have been observed. For instance, subtle effects related to the kinetics of polyelectrolyte reorganization can be observed when considering the flocculation of suspensions at different solids levels. In suspensions of 
low solids content Mangravite et al. (1985) observed an inverse relationship between the charge density of cationic flocculants and the optimum treatment level of flocculation. This dependency disappeared when the tests were repeated in concentrated suspensions. Thus it appears that the frequency of inter-particle collisions may affect whether flocculation is governed by a charge-dependent mechanism or by a bridging mechanism. Analogously, in papermaking applications it has been found that the time delay between two components of a dual retention aid system can be critically important (Petäjä 1980).

\section{Overdose of flocculant}

Users of flocculants commonly observe suboptimal or even undesirable results when the amount of flocculant exceeds an optimum level. Based on the discussion in the previous paragraph it is reasonable to expect there to be an element of unpredictability, depending on how an overdose situation comes about. For instance, at some intermediate point during the process of mixing, the conditions may be ideal for the formation of polyelectrolyte bridges. In that case it is reasonable to expect that the bridges might persist for a while, even if the ultimate amount of polyelectrolyte added to the system is enough to cover all of the exposed surfaces. In other situations the polyelectrolyte may become distributed evenly over the available surfaces, achieving something like a full coverage. In the latter case it is reasonable to expect the polyelectrolyte to act as a dispersant, especially if it has a water-loving nature. Accordingly, Lindström et al. (1974) observed decreasing flocculation in the presence of an overdose of cationic acrylamide copolymer, a finding that suggests at least a moderate degree of reversibility of flocculation.

\section{Steric stabilization and charge stabilization}

If polyelectrolyte molecules are able to cover all of the accessible outer surfaces of solids in a suspension, then there are two main mechanisms by which the polyelectrolytes can act to prevent sticking collisions among the solids. Charge-induced restabilization and electrostatic repulsion between surfaces have been clearly demonstrated in cases where suspensions were treated with highly charged cationic polymers (Holmberg et al. 1997; Österberg 2000; Porubská et al. 2002; Salmi et al. $\left.2007^{a}, \mathrm{~b}\right)$. Alince and Robertson (1974) observed initial flocculation when treating microcrystalline cellulose suspensions with an excess of high-mass polyethyleneimine (PEI); however the system became stabilized after the initial agglomerates were separated by means of hydrodynamic shear. In particular, an electrostatic contribution to colloidal stability can be expected in cases where the polyelectrolyte has the same sign of charge as the suspended particles (Chang et al. 1991; Claesson et al. 2005).

The second mechanism has become known as "steric stabilization." Relatively high-mass, lower charge density polyelectrolytes and polyampholytes, as well as uncharged water soluble polymers such as polyethylene oxide (PEO) can be expected to give rise to this effect (Pelton et al. 1980; Salmi et al. 2007a,b). In principle, regardless of the electrical charge characteristics, the presence of a complete layer of loops and tails of water-loving polyelectrolyte on wetted surfaces can inhibit direct contact between those surfaces. The effect can be attributed to the extra energy that would be needed to move adsorbed loops and tails of adsorbed macromolecules out of the way to enable 
collision between the surfaces. In the case of charged polymers adsorbed onto surfaces it would be reasonable to expect that both electrostatic effects and steric stabilization effects to operate in parallel.

\section{Depletion flocculation}

In the interest of completeness, it has been shown that soluble polymers also can contribute to flocculation even in cases where there is no tendency to adsorb (Fleer et al. 1993; Dahlgren and Leermakers 1995). The effect is observed especially in cases where the polymer concentration is relatively high. In such cases thermodynamics can favor a phase separation, whereby a macromolecule-rich phase separates from the suspended solids. As a consequence, the particles become agglomerated together and the effective interfacial area between the liquid and solids phases is reduced. Though this "depletion flocculation" mechanism hardly makes sense in cases where retention aids interact strongly with the surfaces, i.e. in typical papermaking applications, the mechanism can be reconsidered to explain some of the effects of poly-ethylene oxide (PEO) retention aid systems (Smith-Palmer and Pelton 2002).

\section{Separation of Surfaces}

Because papermaking fiber suspensions are subjected to very strong hydrodynamic forces during and after addition of retention aids (van de Ven and Mason 1981; Tam Doo et al. 1984; van de Ven et al. 2005), it is important to consider what may happen after polyelectrolyte-induced attachments are broken (Swerin and Ödberg 1997). Possibilities include the redistribution of polyelectrolyte molecules to cover the surfaces more thoroughly, reconformation so that polyelectrolyte tails and loops are less extended from the surface, or gradual penetration of polyelectrolyte into the cellulosic material. Though retention aid polymers are often considered to be too large to penetrate into the cell walls of cellulosic fibers, there is a real possibility that they gradually migrate into hidden spaces among cellulosic fibrils at fiber surfaces (Hostetler and Swanson 1974; Lindström and Söremark 1976; Ödberg et al. 1993; Petlicki and van de Ven 1994; Gruber et al. 1996a; Alince and van de Ven 1997; Swerin and Ödberg 1997; Yoon 2007). Also, if breakage of polyelectrolyte chains occurs in the presence of shear forces, it becomes more reasonable to expect that fragments of retention aid molecules can penetrate into narrow spaces.

Some insights into how retention aids function have been gained from experiments evaluating forces needed to break polymer-induced attachments (Britt 1973a, 1981; Tomi and Bagster 1975; Unbehend 1976; Vader and Dekker 1978; Pelton and Allen 1984; Mühle 1985, 1987; Hubbe 1987, 2007; Kamiti and van de Ven 1995; Yeung and Pelton 1996; Yeung et al. 1997; Janex et al. 1997; Goto and Pelton 1999; Åsselman and Garnier 2001; Hubbe and Wang 2002; Tripattharanan et al. 2004a,b). The cited work has shown, for instance, that adhesive forces induced by retention aids can be several factors of ten stronger than what can be achieved just by neutralization of electrostatic charges. 


\section{Reversibility of flocculation}

A number of studies have considered the ability of different suspensions of cellulosic material to become flocculated again after treatment with retention aids, followed by application of intense hydrodynamic shear (Ruehrwein and Ward 1952; Unbehend 1976; Stratton 1983; Swerin et al. 1992; Hedborg and Lindström 1996; Alfano et al. 2000; Tripattharanan et al. 2004a; Hubbe 2000b, 2001, 2007). The shear forces were presumed to be strong enough to break at least some of the polymer-induced attachments. Reversible flocculation generally is consistent with the charge-induced mechanisms of flocculation, e.g. agglomeration that is brought about by the "charged patch" and "neutralization" mechanisms (Tripattharanan et al. 2004b). By contrast, if breakage of polyelectrolyte bridges involves cleavage of macromolecules chains (see next), then it is reasonable to expect that the strength with which the surfaces can be held together again, after further interparticle collisions, will be reduced.

\section{Chain cleavage and transfer}

Evidence of molecular mass reduction accompanying breakage of retention aidinduced fiber flocs has been obtained in key studies (Sikora and Stratton 1981; Ödberg et al. 1993; Tanaka et al. 1993). There are mainly two ways to account for such reductions in molecular mass. On the one hand, high levels of hydrodynamic shear are capable of breaking down macromolecules in free solution (Henderson and Wheatley 1987). Loss of molecular mass, in the case of solutions of linear polymers, can be expected especially when the systems encounter extensional flow, as in the case of flow through a screen or other restriction (Nguyen and Kausch 1992). But it is more reasonable to think that chain-cleavage comes about when solid objects, joined together by polyelectrolyte bridges, are ripped apart from each other by shear forces (Tanaka and Ödberg 1992; Tanaka et al. 1993). It has been proposed that such cleavage is at least partly responsible for the transfer of retention aid polymers from an initial site of adsorption to other surfaces in a papermaking suspension (Åsselman and Garnier 2001). As an alternative mechanism, depending on the strength with which polymer segments are adsorbed, it is possible that tension on a polyelectrolyte bridge could result in peeling off of macromolecules segments from one surface. However, the latter mechanism does not account as well for the pronounced decreases in molecular mass.

\section{Polymer rearrangement after shear}

Whether or not chain cleavage occurs during shear-induced destruction of a polymer bridge, it is reasonable to expect that thermodynamic considerations and the passage of time will favor changes in the conformation of adsorbed retention aid chains (Swerin and Ödberg 1997). Such reorganization can be expected to reduce the tendency of bridges to form again after breakage, especially if it involves less extended tails and loops of polyelectrolyte, or a more uniform coverage of the accessible surfaces. 


\section{CATIONIC POLYACRYLAMIDE (CPAM) RETENTION AID SYSTEMS}

Of the three major ionic classes of retention aid products, cationic acrylamide copolymers are the best known and most widely used (Jaycock and Swales 1994; Horn and Linhart 1996). From a logical standpoint it makes sense to select a positively charged additive as a means of flocculating cellulosic materials. The ability of cationic acrylamide copolymers to adsorb strongly onto cellulose fibers has been convincingly shown (Lindström and Söremark 1976; Tanaka et al. 1999; Zhang et al. 2003).

\section{Chemistry of CPAM and Related Products}

A typical cationic retention aid polymer is prepared by free-radical polymerization in a mixture that contains between 90 and $99 \%$ of neutral acrylamide monomers with the balance of active ingredients consisting of a cationically substituted acrylamide monomer. Commonly employed monomers are shown in Fig. 6 (Horn and Linhart 1991; Pelzer 2008). Besides the quaternary monomers shown in the figure, a dimethylamino version of monomer " $\mathrm{B}$ " can be suitable in cases where the operating $\mathrm{pH}$ of the paper machine is below about 6 . In addition, various new cationic retention aid chemistry have been patented (Kuo et al. 1995; Schuster et al. 1996; Wong Shing et al. 1998; Wong Shing and Hurlock 2000, 2003) or described in the scientific literature (Wang et al. 2003). Ultimately each such product needs to demonstrate cost-effectiveness in comparison to the mainline cationic acrylamide family.

A.

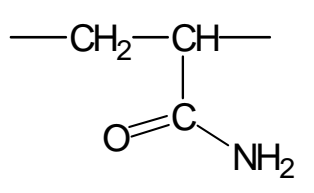

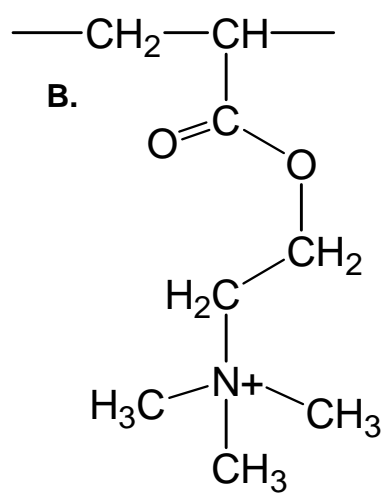

c.<smiles>CC(C)C(C)C(=O)NCCC[N+](C)(C)C</smiles>

Fig. 6. Chemical structures of monomers commonly used for synthesis of cationic acrylamide copolymer retention aid products. A: Uncharged acrylamide monomer. B: Ester-type quaternary ammonium cationic monomer. C: Amide-type quaternary ammonium cationic monomer.

Typical cationic acrylamide retention aid products have molecular mass values in the range of about 4 to 10 million grams per mole. For the sake of convenience in handling such high-molecular-mass products at high levels of active polyelectrolyte, the polymerization is often carried out in a "water-in-oil" emulsion with a suitable nonionic surfactant to keep the emulsion droplets from coalescing. In addition to the emulsion form of delivery, cationic retention aids also are sometimes supplied to the user in the form of tiny dry beads, which need to be carefully added to water under conditions of high dilution and well-controlled agitation. In principle, retention aids also could be delivered in solution form; however, such practices would necessitate the shipping of a 
very large proportion of water, depending on the molecular mass. For this reason, suppliers and users tend to prefer the shipping of aqueous polyelectrolyte solutions only when the molecular mass is less than about 2 million grams per mole.

There also has been progress in creating various innovative kinds of formulations to address concerns associated with conventional water-in-oil emulsion technology. For instance, some users would like to limit the mount of mineral oil used in their operations. Feng et al. (2001) described a system in which an aqueous solution of high-charge cationic polymer was used as the continuous phase for dispersing particles of high-mass cationic retention aid. Presumably the electrolyte levels in the concentrate were selected so as to suppress solubility of the dispersed tiny beads of retention aid polymer. Similarly, Maury et al. (1998) patented a system for high-actives flocculant polymer dispersed in an aqueous solution in which there was a sufficiently high concentration of various ions to inhibit solubilization before dilution and use of the product. Wong Shing et al. (2002) patented related technology involving a polymeric stabilizer.

Natural product derivatives, cationic starch in particular, are often considered as potential competitors to cationic acrylamide copolymer products. The ability of cationic starch to flocculate cellulosic fibers is well known (Roberts et al. 1986). However, it is generally observed that cationic starch is a less effective flocculant in comparison with cationic acrylamide products. On a price basis starch is often considered to be a superior product for increasing the dry strength of paper products (Hubbe 2006). A recent article by Gaiolas et al. (2006) advocates successive addition of cationic starch and cationic acrylamide during papermaking in order to achieve a combination of retention and dry strength benefits. Buontempo (1996) likewise showed synergistic relationships between cationic starch and cationic retention aids; it was found that pretreatment of the fiber suspension with cationic starch tended to promote the effectiveness of the retention aids. Chi et al. (2007) showed that a quaternized chitosan product also was effective for the retention of calcium carbonate filler in paper.

Amphoteric polymers also have been considered for use as retention aids. Thus, Lu et al. (2001) observed that acrylamide-type terpolymers having both positively and negatively charged ionic groups were equally effective as retention aids as a cationic flocculant, which was used as a reference. As has been also observed in recent studies of dry-strength additives (Song et al. 2006), the performance of the polyampholytes as retention aids can be enhanced by pretreatment of the furnish with aluminum sulfate (Lu et al. 2001). As shown in a recent article (Wang et al. 2006), polyampholytes can be expected to adsorb onto charged surfaces under a wide variety of circumstances, including either positive or negative net charge of the surface. This capability is attributed to the ability of polyampholyte molecules to rearrange their conformation in an electrically polarized manner, such that charged groups opposite in charge to the surfaces tend to be enriched at the interface. It is possible that the accommodating nature of polyampholytes might allow them to perform well as retention aids in many situations.

\section{Preparation of cPAM Solutions}

Emulsion-type retention aid formulations, which typically have "actives" levels of 25 to $65 \%$, need to be "inverted" before use. In other words, the internal, aqueous phase needs to become the continuous phase, as a result of controlled agitation with a high ratio 
of dilution water. Sufficient dilution water must be used during the inversion such that the viscosity of the resulting mixture is low enough for practical mixing and pumping. As an example, it is possible that the dilution is carried out in two stages, with the initial "make-down" resulting in a solids level of $1 \%$ polymer. It is usually recommended to allow the diluted mixture to stand, possibly with gentle stirring, for 20 minutes or an hour before use. The storage time permits the macromolecules, which had been tightly coiled up in their emulsified state, to uncoil themselves and achieve a more expanded conformation. Thereafter it is common to use further dilution water to transport the retention aid to its point of injection into the fiber suspension, often at a solids level of $0.2 \%$ or less.

Ryösö and Manner (2001) considered the effects of anionic colloidal matter during dilution of retention aid products. The colloidal matter has the potential to form polyelectrolyte complexes, thus using up some of the ability of the retention aid to interact with negatively charged surfaces in cellulosic fiber suspensions. The authors found that such complexes could be avoided by removal of the anionic colloids from the dilution water, by reducing the amount of dilution employed, by minimizing the time of contact with water from the process, or by using a cationic retention aid of sufficiently low charge density that it did not form strong complexes. Membrane filtration was recommended as a possible way to remove the high-mass component of dissolved and colloidal matter from paper mill process water. Maltesh and Shing (1998) similarly found that anionic colloidal material in the dilution water tended to hurt the performance of cationic retention aids.

\section{Factors Affecting the Flocculating Effectiveness cPAM}

Some of the key factors expected to affect the flocculating effectiveness of cationic retention aids are the amount added, its charge density, and its molecular mass. Details of molecular structure also are likely to have an effect on flocculating performance, though possibly to a lesser extent.

\section{Charge density}

Several studies have identified charge density as a key factor affecting the performance of cationic retention aids. Laboratory studies by Lindström et al. (1976) and Eriksson and Alm (1993) observed highest flocculating effectiveness with relatively lowcharge cationic acrylamide. Both of these studies were carried out in the absence of anionic contaminants. In the presence of anionic dissolved and colloidal material Lindström et al. (1974) and Polverari and van de Ven (1996) observed increasing effectiveness of cationic retention aid with increasing charge density. Nurmi et al. (2003) reported, surprisingly, that anionic dissolved and colloidal matter from thermomechanical pulp did not interfere with the function of cationic retention aids having a wide range of charge density. Fallon (1992) patented the use of a relatively high-charge cationic retention aid for purposes of achieving retention while minimizing the flocculation of fiber suspensions.

Evidence of the importance of charge density of the cationic flocculant was shown in Fig. 1, which comes from earlier work by the authors. Part A of the figure shows a very extended conformation in the case of a low-charge-density cPAM retention 
aid. Part B shows a more strongly agglomerated system, in which a higher-charge density cPAM flocculant has interacted with cellulosic matter at fibril surfaces.

\section{Electrolyte concentrations}

Figure 7 illustrates effects of electrolyte concentration on the behavior of a cationic acrylamide copolymer during its interaction with cellulosic fines (Nanko et al. 2006). In the absence of salt (e.g. transmission electron micrograph in left-hand frame of Fig. 7) it is reasonable to expect that the polyelectrolytes will adopt an extended conformation in solution (though the "stretched" appearance of the polyelectrolyte strands in the figure has been attributed to flow effects). In the presence of salt (e.g. right-hand frame of Fig. 7) one observes a conformation that probably is more realistic for actual papermaking operations; a more condensed conformation of adsorbed cationic polyelectrolytes under such conditions is consistent with a shorter range of electrostatic repulsion forces in the presence of salt ions. Though these interpretations of the images are consistent with colloid chemical principles, more research is needed, following up on these unique observations.

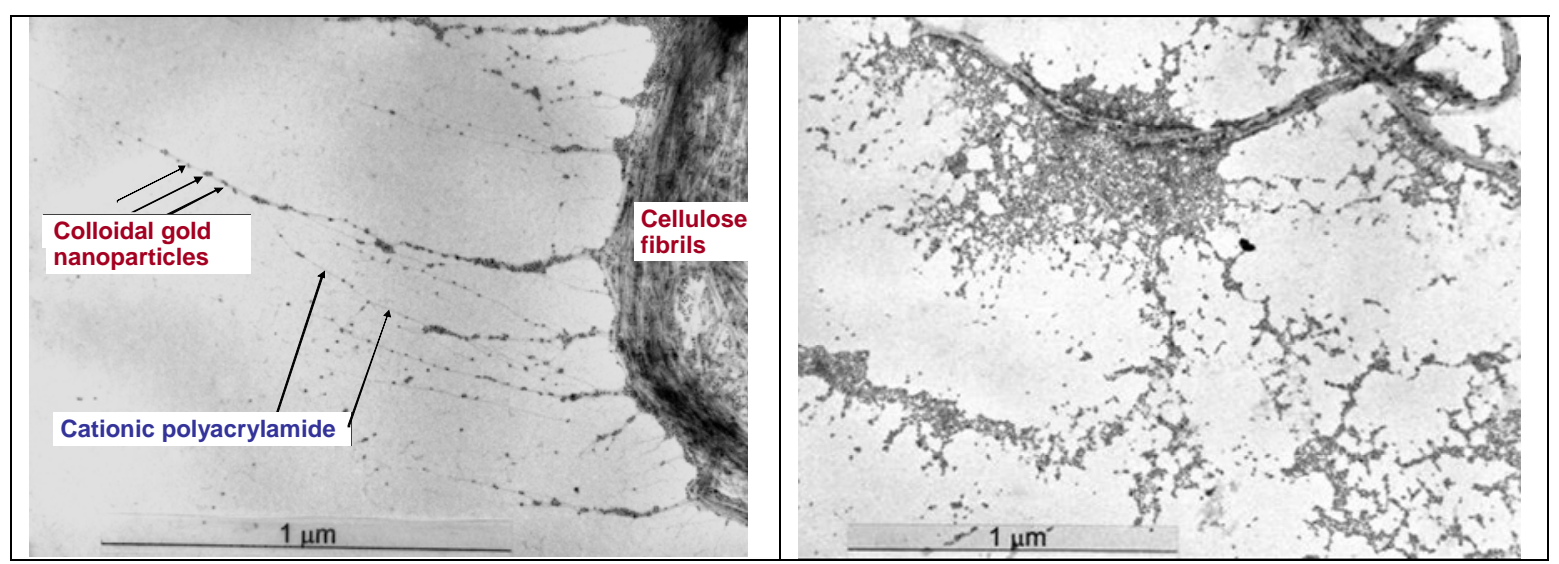

Fig. 7. TEM images showing effect of polyelectrolyte charge density on the adsorbed conformation of cationic acrylamide copolymer retention on cellulose fibrils. Part A: Low charge density CPAM at low ionic strength; B: Same flocculant treatment in presence of 1000 ppm sodium sulfate $(455 \mu \mathrm{S} / \mathrm{cm})$.

\section{Molecular mass}

Several studies have documented increased effectiveness of cationic retention aids with increasing molecular mass (Lindström et al. 1976; Gill and Herrington 1987; Wang et al. 2003; Zhang et al. 2003). As noted by Fleer and Lyklema (1974), higher molecular mass is expected to yield greater bridging ability. Lindström et al. (1974) also observed an increased effect on zeta potential with increased mass of cationic acrylamide copolymer; presumably this effect is due to greater extension of polymeric loops and tails outward from the surface, as well as a reduced rate of migration of larger polymers to locations buried within the fibrillated surface of cellulosic fibers. Polverari et al (2001) found that the performance of higher-mass cationic retention aids was less affected by the presence of anionic dissolved and colloidal matter. 


\section{Macromolecular structure}

A practical means of achieving increased molecular mass, as well as a branched structure involves addition of a minor amount of multi-functional unsaturated monomer to the reaction mixture during preparation of the polymer. For preparation of a cationic retention aid, this approach was described in a patent by Hansson and Jachimowicz (1984, 1985). Yoon and Park (2005) showed that both branched and linear cationic acrylamide copolymers were able to flocculate stock solutions in the presence of fillers and microparticles. In the absence of fillers it was found that the branched copolymers yielded paper sheets having more uniform formation, which was helpful in terms of higher physical strength and more rapid release of water during the paper forming process.

As shown by Allen and Polverari (2000), a class of very highly branched, symmetrical macromolecules known as dendrimers can be used as cationic retention aids. Surprisingly, these authors did not find any change in effectiveness with increasing molecular mass; these results suggest that the observed effects were mainly related to charge neutralization. Shin et al. $(1997,1998)$ reported related work. Their flocculants produced a dense, fine flocculation effect, which also is consistent with a chargedependent mechanism.

Fu et al. (2007) described an innovative approach in which a five-armed molecule was prepared, starting with pentaerythritol at its core. This cationic retention aid molecule was found to perform well as a retention aid over a wide range of $\mathrm{pH}$ and hydrodynamic shear.

\section{Addition point of $C P A M$}

As a general principle, the greatest effectiveness of retention aids can be achieved when they are added as late as practical to the paper machine system. As shown by Räisänen et al. 1994, only a few seconds are needed in order to achieve optimum interaction between the retention aid polymers and solid surfaces in a fibrous suspension. Additional exposure to fibers, especially at the high shear levels prevailing in modern paper machine systems, is expected to degrade the molecular mass and distribute the macromolecules in a flatter adsorbed conformation. Hubbe and Wang (2002) used laboratory methods to compare two different strategies for retention aid addition, either before or after application of hydrodynamic shear, representing the passage of stock through the pressure screen system of a typical paper machine. The latter strategy, though it caused a measurable reduction in retention aid effectiveness, also tended to redisperse fiber flocs. For many grades of paper it is important to achieve a balance between uniform formation, in addition to the benefits of higher first-pass retention. In cases where it is considered to be more important to minimize the cost of achieving a selected target of retention efficiency, it may make more sense to employ "post-screen" addition of the retention aid.

\section{Order of addition}

Some imaginative investigators have tested a reverse order of retention aid. In other words, the retention aid was added ahead of the material to be retained. Thus, Waech (1983) achieved higher retention of clay and $\mathrm{TiO}_{2}$ when using a reverse order of 
addition. Miller and Stratton (1990) showed that reverse addition was able to achieve higher levels of retention of latex particles under the conditions of testing. Ryösö (2001) observed that a reverse order of addition was effective for retaining filler, while also minimizing the adverse effect of retention aid on formation uniformity. Greatest effectiveness was found if the delay time between retention aid addition and filler addition was minimized.

Though all of the cited studies showed promise for reverse order of retention aid addition, it is likely that such benefits are not enough to overcome some practical considerations in most paper mills. First, as already mentioned, a retention aid tends to lose its effectiveness with increasing time in contact with an agitated suspension of fibers. Any time that retention aid is placed "before" other additives, that move necessarily increases the time during which the retention aid will be exposed to hydrodynamic forces. Also, if a major additive such as filler were added very late to the paper machine system, for instance just before the flow distribution system for a paper machine headbox, then an uneven distribution across the width of the paper machine would be expected in many cases. Wang et al. (2003) tested different orders of addition to retain a sizing agent and concluded that a conventional order of addition, with the retention aid after the sizing agent, worked best.

\section{Charge decay}

Electrokinetic measurements have provided further insights into the behavior of cationic polymers at cellulosic surfaces. Several studies have shown a gradual "decay" of zeta potential with the passage of time after the addition of a cationic polymer to fiber slurries (Strazdins 1977; Lindström and Söremark 1976; Farley 1997; Koethe and Scott 1993; Hubbe et al. 2007a). This kind of observation can help to explain why the amount of cationic polymer needed to achieve neutral charge tends to increase with increasing time delay before the electrokinetic measurement (Goossens and Luner 1976). In the case of low to moderate mass polymers such observations usually are attributed to gradual penetration of the polyelectrolytes into pores. However, it would appear that a different explanation is needed to account for the very precipitous changes in zeta potential with time in the case of cationic retention aids (Koethe and Scott 1993). Due to the very high molecular mass of the retention aids, it is not reasonable to attribute the rapid decay of zeta potential to diffusion or penetration. Rather, one has to assume that the effect is due to changes in polyelectrolyte conformation during the first seconds after addition of the retention aid. During the initial moments of adsorption it is reasonable to expect that the adsorbed polymer may have a three-dimensional, semi-random molecular conformation. Alternatively, it is possible that the adsorbed chains are in a stretched conformation, corresponding to the images in Fig. 1. The extension of the charged segments out into the solution phase may explain a strong initial effect on zeta potential, but the effect is expected to diminish rapidly as the polymer adopts a flatter adsorbed conformation. The fact that, at higher levels of addition, the amount of cationic retention aid that can be adsorbed exceeds the amount of negative groups on a surface (Tanaka et al. 1999) provides circumstantial evidence that, at least initially, the polymer has a threedimensional adsorbed conformation. 


\section{Pretreatment with Highly Charged Cationic Additives}

Many studies have shown improved performance of cationic retention aids in cases where the papermaking furnish was pretreated with an optimized amount of highcharged cationic polymer (Swerin et al. 1997; Nässman et al. 1998; Dunham et al. 2000; Kamijo and Miyanishi 2002; Xu et al. 2007) or with a soluble aluminum compound (Harrington and Schuster 1996; Wang and Tanaka 2000). In related findings, Spence et al. (1999) patented a combination of high-charge poly-DADMAC and glyoxylated polyacrylamide as a retention and drainage system.

\section{Neutralization of dissolved and colloidal substances}

One way to account for beneficial effects of pretreatment with high-charge cationic materials is to assume that polyelectrolyte complexes are being formed with the anionic dissolved and colloidal materials (DCS) present in the mixture (Pietschker et al. 1993; Wågberg and Aselli 1995; Maltesh and Shing 1998; Nässman et al. 1998; Dunham et al. 2000; 2002; Ryösö and Manner 2001; Nurmi et al. 2004; Bhardwaj et al. 2005; Xu et al. 2007). The mechanism is diagramed in Fig. 8. As illustrated in part $\mathrm{A}$ of the figure, it can be expected that the cationic retention aid copolymers will begin to form polyelectrolyte complexes with the DCS. Depending on the level of DCS, the result may be as suggested by the figure, i.e. the formation of neutralized agglomerates of fine material. Rather than being able to interact strongly with the fiber surfaces, much of the added polyelectrolyte may remain tied up with the agglomerated colloidal matter. As shown in part B of the figure, it makes more sense to neutralize the colloidal material in a more economical manner, employing relatively high-charge, lower-mass additives such as alum, PAC, or various polyamine products. As suggested in part B, subsequent addition of a cationic retention aid then can be expected to be much more effective as a bridging agent, since the high-mass polymer is able to maintain its positive charge and extended conformation in solution.
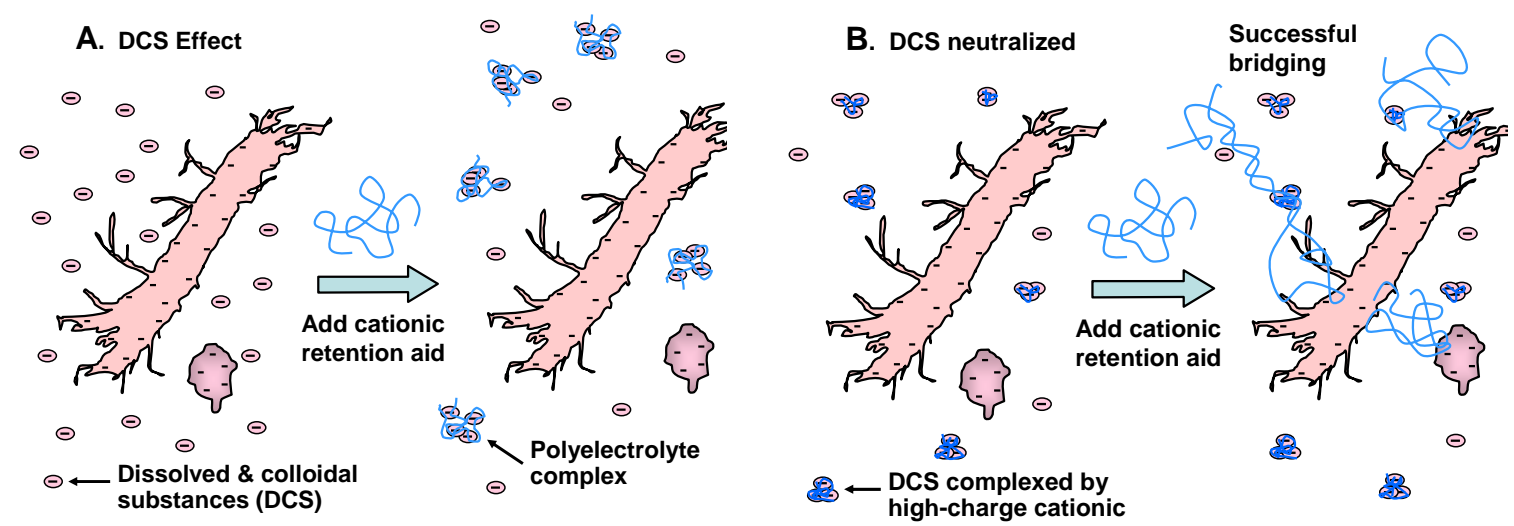

Fig. 8. Cartoon illustration to account for the adverse effect of dissolved polymeric and colloidal anionic substances (DCS) on the performance of cationic retention aids (left) and the ability of a high-charge cationic pretreatment to neutralize the charge of DCS and allow the performance of the cationic polymer to be maintained (right) 


\section{Site-blocking and competition for adsorption sites}

Another way to account for the beneficial effect of high-charge-density cationic pretreatments before addition of cationic retention aids is called "site blocking" (Swerin et al. 1997). This mechanism is illustrated in Fig. 9. The idea is that the lower-mass cationic material is able to quickly occupy a substantial proportion of the accessible surface area on the solids in a fiber suspension. Then, when cationic retention aid is added subsequently to the suspension, the long-chain molecules still are able to adsorb onto the remaining negatively charged areas of the solids. However, the blocking polymers prevent the flocculant molecules from spreading out on the surface. The resulting three-dimensional conformation in the adsorbed state is expected to be favorable for bridging interactions.

A. No site-blocker present

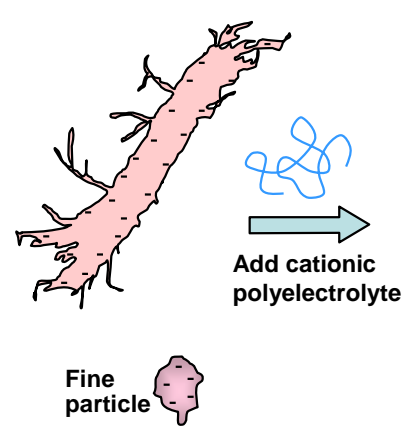

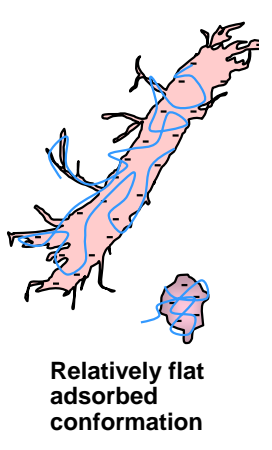

B. After pre-treatment with site-blocker

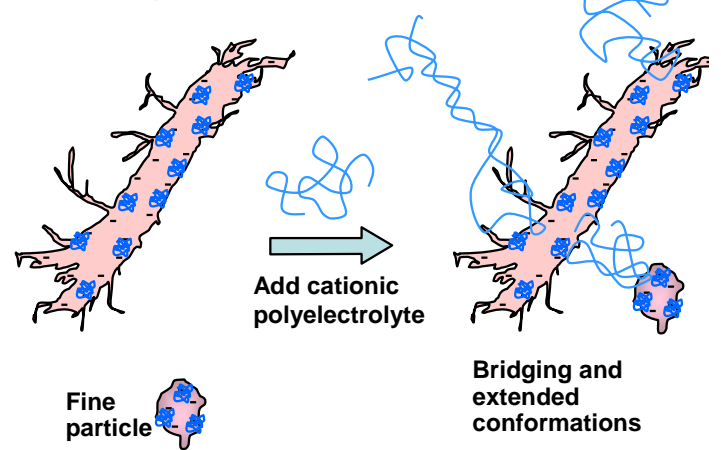

Fig. 9. Illustration of site-blocking mechanism to account for the beneficial effect of pretreatment of the furnish with high-charge cationic polymer on the performance of a cationic retention aid even in the absence of DCS. A: Tendency of the retention aid polymer to adopt a flat adsorbed conformation, especially with the passage of time. B: Partial coverage of cellulosic surfaces with high-charge cationic polymer may prevent CPAM molecules, added later, from lying down rapidly on cellulosic surfaces; this sequence can favor the occurrence of bridging flocculation.

\section{Salt effects}

Salts are another component of paper machine process water that is expected to adversely affect the performance of retention aids (Lindström et al. 1976; Buontempo 1996; Maltesh and Shing 1998; Xu et al. 2007). One explanation for this effect is that the random coils of polyelectrolyte are expected to become less expanded with increasing salt (Beer et al. 1997; Rojas et al. 1998; Ariel and Andelman 2003). This effect is sketched in part A of Fig. 10. The contraction is attributed to a screening of electrostatic repulsive forces as a result of salt ions occupying the spaces between ionic groups along the polyelectrolyte chain. Alternatively, the effect also can be called an osmotic effect, whereby the salt decreases the tendency of the cationic polyelectrolytes to swell in water due to their charged nature.

One of the expected consequences of a less extended conformation in the adsorbed state is that a flocculating polymer is not expected to be able to reach as far from one surface and form bridging interactions with an adjacent surface. Accordingly, Gregory (1973) found that salts tended to slow down the rate of polymer-induced flocculation, presumably because the salt decreased the effective size of the flocculant 
molecules. This explanation is consistent with the TEM images shown in Fig. 7. The situation is tricky, though, since salts also can weaken the interactions of a cationic polyelectrolyte with a substrate; such observations can explain a somewhat more extended conformation at intermediate salt concentrations as measured sometimes by ellipsometry (Shubin and Linse 1995).

It has been observed that the adsorbed amount of cationic polymer tends to first increase with salt addition, but then decrease (Lindström and Wågberg 1983; Solberg and Wågberg 2003b). This phenomenon is sketched in part B of Fig. 10. As suggested by the figure, very low salt concentration (e.g. $<0.1 \mathrm{mM}$ salts; $<200 \mu \mathrm{S} / \mathrm{cm}$ conductivity) is expected to promote relatively rapid polyelectrolyte adsorption, resulting in a relatively flat adsorbed conformation. Such results are an expected consequence of the relatively long range of electrostatic interactions in the absence of salt (e.g. $20 \mathrm{~nm}$ or greater). At intermediate salt concentrations (e.g. $1-10 \mathrm{mM} ; 0.5$ to $5 \mathrm{mS} / \mathrm{cm}$ conductivity) a larger quantity of polyelectrolyte is expected to be able to interact with the cellulosic surfaces, due in part to the less extended conformation of the polymers in solution. Also, since the electrostatic interactions are shorter in range, there is less of a driving force for the polyelectrolyte to adopt a flat adsorbed conformation. The right-most sketch in part B suggests that at sufficiently high electrolyte concentration the interactions between a polyelectrolyte and a cellulosic surface may be so weakened, partly as a result of competition with small ions for the same adsorption sites, that much of the polyelectrolyte remains in solution. It should be kept in mind, however, that even in the absence of electrostatic attractions, retention aid polymers are sufficiently large that it is reasonable to expect some degree of entanglement with cellulosic fibrils in a stirred suspension of fibers.
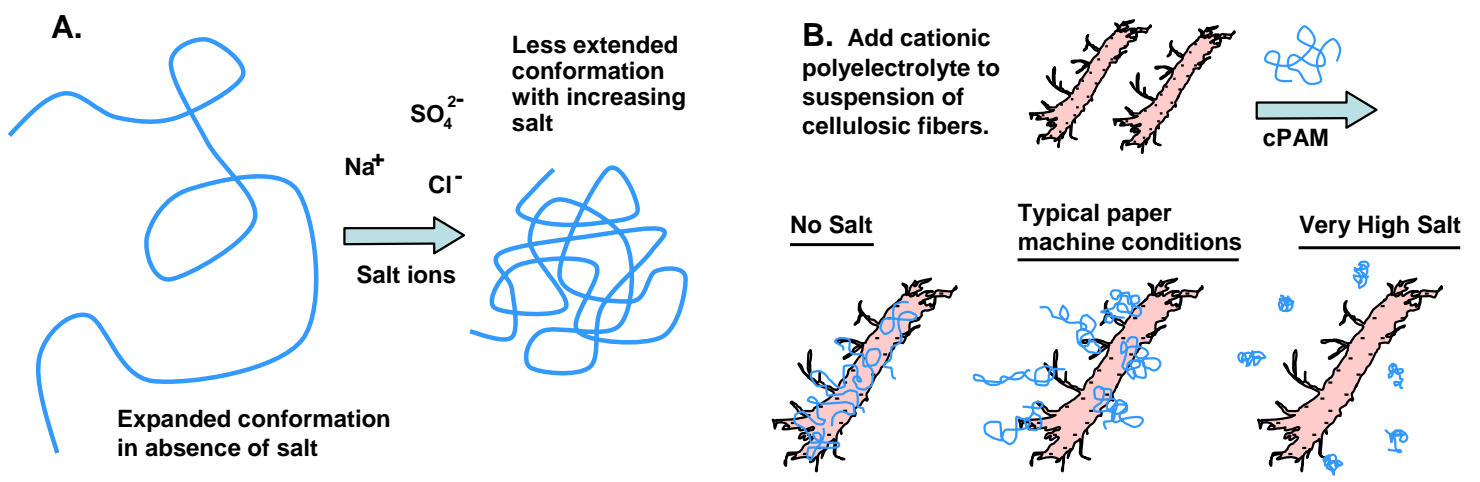

Fig. 10. Effects of salt on the conformation of a high-mass cationic polyelectrolyte. A: Conformation in solution. B: Conformation when adsorbed onto a cellulosic surface at low, intermediate, vs. high electrolyte concentration.

The tendency of high salt concentrations to weaken interactions between cationic polyelectrolytes and negatively charged surfaces has been well demonstrated in the case of cationic starch. As salt levels become higher than about $0.01 \mathrm{M}$, the tendency of the cationic starch to adsorb onto negatively charged surfaces will be decreased (van de Steeg et al. 1992; Holmberg et al. 1997). Henderson and Wheatley (1987) found that increasing salt can reduce the tendency for deterioration of cationic retention aid 
performance during agitation. Presumably this is yet another consequence of having a less expanded molecular conformation in the presence of salt.

\section{Reversibility}

Consistent with a bridging mechanism of flocculation, various studies have shown that fiber flocs formed with cationic acrylamide retention aids do not form again to the same extent after application of strong hydrodynamic shear (Beck et al. 1977; Swerin et al. 1992, 1997; Hedborg and Lindström 1996; Forsberg and Ström 1994; Horn and Linhart 1996; Swerin and Ödberg 1997; Hubbe 2000b; Tripattharanan et al. 2004a). However, one article reported contrasting observations; reversible flocculation by cationic acrylamide copolymers was observed by Eriksson and Alm (1993) in a study involving latex suspensions; there is reason to believe that a "charged patch" mechanism was operating in that case. In the other cases it is often reasonable to assume that some retention aid polymers are degraded during hydrodynamic break-up of fiber flocs, or at least the retention aid polymers are able to adopt flatter conformations that are less amenable to forming bridges again with adjacent surfaces.

\section{Microparticle Systems with cPAM}

Reviews of microparticle-based retention and drainage additives systems have been given elsewhere (Wågberg and Lindström 1987; Swerin et al. 1997; Gruber and Müller 2001; Hubbe 2005), so only a brief summary will be given here in the context of cationic retention aid use. Such systems characteristically employ a pair of agents added sequentially. A cationic acrylamide copolymer, i.e. a cationic retention aid, is typically one of the additives, though cationic starch products were used in the earliest applications of microparticle retention and drainage systems. The other main additive, which is added sequentially, can be either colloidal silica, sodium montmorillonite (bentonite), or various organic agents that play a similar role as that of the colloidal silica or bentonite.

\section{Colloidal Silica Systems}

Colloidal silica is a synthetic product formed by the controlled acidification of sodium silicate solutions. Important attributes of colloidal silica, from the standpoint of retention and drainage include primary particle size (inversely related to the surface area), and also the degree to which primary particles are fused together into chains, i.e. gel content (Andersson and Lindgren 1996). A greater degree of structure, i.e. gel content, tends to favor higher retention efficiency, which is attributed to a greater ability of microparticles having higher aspect ratios to complete bridges that involve cationic retention aid molecules adsorbed onto facing surfaces in a suspension. The chemical nature of the microparticle also can be varied (Chung 1991). Kuo et al. (1995) patented a cationic polymer retention aid expressly intended for use with colloidal silica as a retention aid program. Solberg and Wågberg (2003b) observed a complex interaction between cationic acrylamide copolymers and colloidal silica, with maximum interaction at salt concentrations in the range of 10 to $100 \mathrm{mM}$ of $\mathrm{NaCl}$. At an optimum ratio of cationic retention and colloidal silica the interaction can lead to substantially faster dewatering of paper webs, and optimum conditions are often associated with an approximate neutralization of the system charge. 


\section{Bentonite Systems}

The other major microparticle system being used on paper machines around the world is based on a natural clay product, sodium montmorillonite, which is commonly called bentonite (Durand-Piana et al. 1987; Miyanishi and Montegi 1996; Schuster et al. 1996; Dunham et al. 2000; Zhang et al. 2003; Cho et al. 2006; Dong and Liu 2006). Because of their very thin, plate-like nature, bentonite particles tend to yield good retention efficiency when added sequentially with a cationic retention aid. In the most widely used practices, the retention aid is added to the system first, usually before the stock passes through a screening system, and the bentonite is added "post-screen."

\section{Organic microparticles}

Several authors have described $100 \%$ organic suspensions that mimic many of the behaviors of colloidal silica or bentonite products when used sequentially with cationic retention aids (Honig et al. 2000; Adamsky and Williams 1996; Vaughan 1996; Vaughan et al. 1998; Mei et al. 2006). Important attributes of these organic products include high negative charge density, and a somewhat structured, three-dimensional form. Somewhat different effects of some organic microparticles (or "micropolymers"), compared to bentonite, prompted the development of a combined system. Thus, according to Liu (2005), the relative proportions of bentonite and organic microparticle can be varied in order to fine-tune the balance between retention and dewatering effects.

\section{Mechanisms of microparticle action}

Microparticle systems are noted for providing a combination of drainage promotion and enhancement of fine-particle retention. It is easy to demonstrate in the laboratory that addition of colloidal silica or bentonite to an otherwise untreated suspension of cellulosic fibers will have almost no effect on either retention or dewatering. Rather, the effects depend on interactions involving both the retention aid molecules and the negatively charged microparticles. Strong electrostatic attraction can be expected between the high-mass cationic polyelectrolytes and the strongly negative surfaces of the microparticles. In addition, lab work has shown that maximum dewatering and retention effects often coincide with a balance of positive and negative charges (Andersson and Lindgren 1996; Hubbe 2005). Another often-observed characteristic of microparticle-based retention and drainage systems is that flocs are able to form again after brief application of hydrodynamic shear (Hedborg and Lindström 1996; Swerin et al. 1997; Hubbe 2001).

It has been challenging to develop a clear picture of how microparticle systems function at a molecular level. There is some evidence that addition of microparticles to a fiber suspension already treated with a cationic acrylamide copolymer causes a drawingtogether of the macromolecular loops and chains, resulting in a densification of the agglomerated cellulosic material (Carlson 1990; Burgess et al. 2000). Confirmatory evidence of such an effect was shown in transmission electron micrographs reported by Nanko et al. (2006); "before and after" pictures showed that the addition of structured colloidal silica to a system already treated with cationic PAM caused the polyelectrolyte chains to draw closer to the cellulosic surfaces and to thicken, such that macromolecular 
chains did not extend outwards as far into the solution phase. In other microscopic views there was evidence of polyelectrolyte networks induced by addition of the structured colloidal silica. Interactions between the cationic retention aid molecules and the microparticles also resulted in a unique feature, which the authors called "radials." These appeared to be composed of stretched polyelectrolyte chains radiating from a central densified zone. It is reasonable to suppose that the densified zone may have been due to complexation between microparticles and segments of the cationic polyelectrolytes. The microscopic evidence has not been completely explained, and more research will be needed to understand the origins and effects of radials.

\section{ANIONIC POLYACRYLAMIDE (aPAM) RETENTION AID SYSTEMS}

When considering their very widespread use within the paper industry, it is surprising how little attention anionic polyacrylamide retention aids have received in the scholarly literature. Some notable exceptions to this rule can be listed (Unbehend 1976; Petäjä 1980; Wågberg and Lindström 1987; Smith-Palmer and Pelton 2002). The most commonly used anionic retention aids are copolymers of acrylamide and about 10 to $30 \%$ acrylic acid, ensuring that they have a moderately strong negative charge within the range of $\mathrm{pH}$ typically employed in papermaking, i.e. $4<\mathrm{pH}<9$.

\section{Performance of aPAM Retention Aid Systems}

Various authors have reported favorable performance of aPAM products for the retention of fines during paper formation (Unbehend 1976; Petäjä 1980; Dennis and Ellms 1982; Wågberg and Lindström 1987; Smith-Palmer and Pelton 2002; Richardson and St. John 2003; Ibrahem et al. 2005). Anionic PAM retention aids have been shown to be particularly effective for retaining certain calcium carbonate products that are widely used as fillers for printing grades of paper (Dennis and Ellms 1982). Although such results make logical sense, due to the positively charged character of calcium carbonate, especially in the absence of dispersants, it would be a mistake to conclude that cationic retention aids cannot be used. Rather, in many cases anionic and cationic retention aid programs can be used almost interchangeably, following careful evaluation and optimization.

\section{Anchoring Sites}

One of the first questions to consider, when dealing with anionic retention aids, is the means by which such additives can attach themselves to cellulosic surfaces. Nedelcheva and Stoilkow (1977) addressed the issue directly, measuring the adsorption on cellulose fibers by PAM having $18 \%$ carboxylic acid content. Significant adsorption was detected, even in the absence of any multivalent cationic additives.

More typically, applications of dual-component retention aid systems with aPAM involve a pretreatment of the stock with a suitable high-charge cationic agent (Petäjä 1980; Wågberg and Lindström 1987). The concept of an anchoring site is illustrated in Fig. 11. 


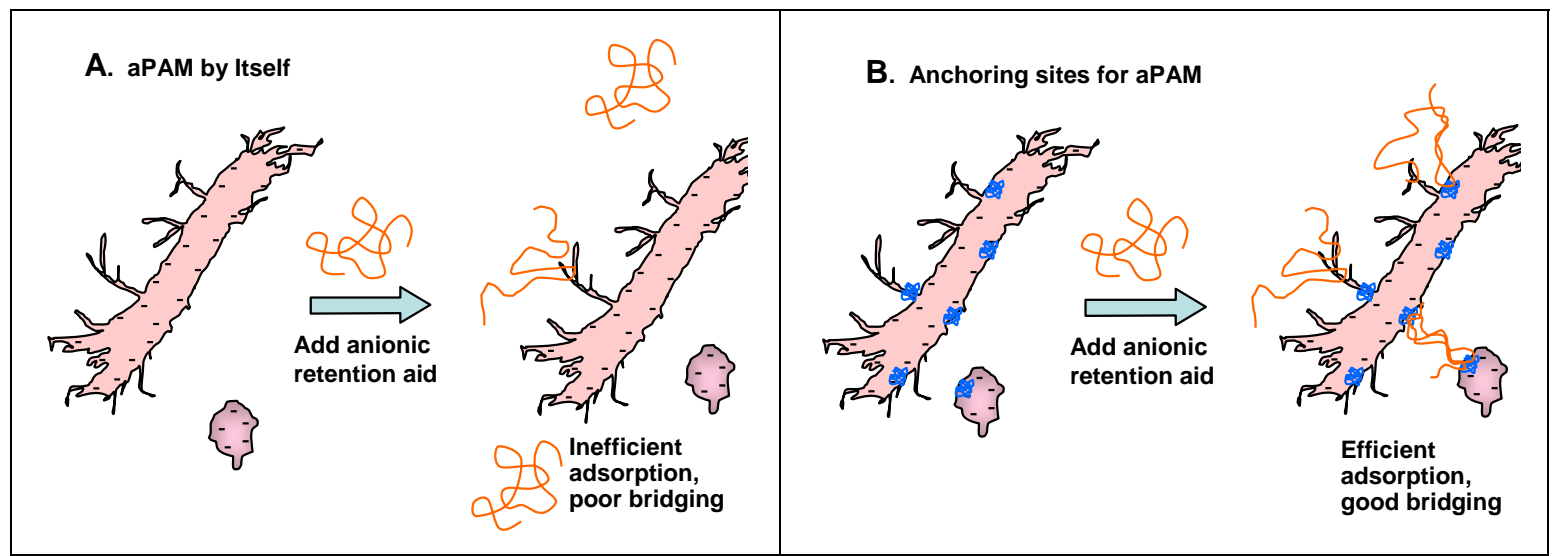

Fig. 11. Illustration of the "anchoring site" concept, to explain the effectiveness of anionic retention aids, especially in systems freshly treated with high-charge cationic additives. A: Lack of efficient adsorption and bridges in untreated suspension of cellulosic materials, where the prevailing surface charge is negative. B: Effective adsorption and bridging, making use of cationic sites on the respective surfaces.

\section{Aluminum coagulant-based}

Early concepts related to dual-component flocculant systems, employing alum as one of the components, already were discussed by Erspamer (1940). An anionic flocculant in use at the time of that writing was prepared from a mixture of animal glue, rosin, aluminum sulfate, and formaldehyde, all of which were matured at low temperature before use. A strong flocculating effect could be achieved by adding this material in sequence with freshly added aluminum sulfate.

In more recent developments it has been found that alum can be an excellent pretreatment of papermaking stock before addition of aPAM retention aid (Arno et al. 1974; Moore 1976). Arno et al. (1974) found that zeta potential could be monitored as a means of optimizing performance of such systems, but only when alum was used as the first additive. Richardson and St. John (2003) demonstrated the use of polyaluminum chloride (PAC) as an alternative to aluminum sulfate for pretreatment of stock before addition of aPAM retention aid.

\section{Pretreatment of system with cationic polymer}

Even greater effectiveness often has been observed in systems where the stock was first treated by a high-charge cationic polymer, and then with a high-mass anionic acrylamide retention aid (Britt 1973a,b; Britt and Unbehend 1976a,b; Moore 1976; Beck et al. 1977; Müller and Beck 1978; Nelson 1978; Petäjä 1980; Wågberg and Lindström 1987; Peltzold et al. 1996). It is reasonable to expect that the high-charge cationic polymer adsorbs onto the cellulosic and other surfaces, thus providing positively charged anchoring sites for the anionic retention aid. Moore (1976) and Petzold et al. (1996) found that overall performance depended on having an optimum balance of charge. Müller and Beck (1978) noted favorable performance of a system in which the highcharged cationic additive was polyethylene-imine (PEI), a highly branched polymer. Voigt and Pender (1978) patented the use of cationic starch as a pretreatment for systems in which aPAM was used as the retention aid. It was noted in some of these studies that 
strong agitation hurt retention in an irreversible manner (Britt and Unbehend 1976a,b; Nelson 1978).

An early strategy with sequential addition of oppositely charged polyelectrolytes was almost the reverse of what has just been described. Fowler (1977) reported success when adding an anionic polymer to the thick stock, followed by cationic PAM retention aid before the headbox. Presumably the pretreatment with anionic polymer could improve the effectiveness of certain cationic retention aids, especially in systems that otherwise would be out of balance on the positive charge side. Another relatively early strategy bearing some similarity to the "dual polymer" systems described here was reported by Arledter and Mayer (1975). These authors mainly considered using PEI as a pretreatment before neutral polyethylene oxide (PEO) retention aid. However, comparative tests showed that the sequential addition of PEI and aPAM also was very effective as a retention aid system.

\section{Molecular Mass of aPAM}

Relative to cationic acrylamide retention aid products, the molecular masses of commercially available anionic acrylamide retention aids tend to be on the high side, i.e. higher than 10 million grams per mole. Higher molecular mass is expected to improve the effectiveness of anionic retention aids (Petzold et al. 1996), although the make-down and handling of retention aids can be expected to become increasingly challenging at the upper limits of molecular mass.

Studies also have shown that the time delay between the respective additives in a "dual" retention aid system involving aPAM can be important. Petäjä (1980) observed optimum times in the range 2 to 10 seconds between a high-charge cationic additive and addition of aPAM.

\section{Polyelectrolyte Complexes}

In systems where cationic and anionic products are added in close succession, it is worth considering whether the two types of products are likely to come into direct contact before being adsorbed onto cellulosic materials (Buchhammer et al. 1993, 1994; Kekkonen et al. 2001; Gernandt 2003; Gärdlund et al. 2005; Lofton et al. 2005; Feng et al. 2007a,b). If positively and negatively charge polyelectrolytes are mixed, before at least one of them has had a chance to adsorb onto solid surfaces, then one can expect polyelectrolyte complexes to form. The cited articles report cases in which such complexes were efficiently retained on surfaces of cellulosic fiber suspensions. Petzold et al. (1998) considered the possible application of polyelectrolyte complexes as flocculating agents. Formation of relatively dense flocs was observed in fiber-free systems; such behavior could be an advantage in water treatment applications. Salmi et al. (2007b) showed that polyelectrolyte complexes having a net positive charge were able to promote strong attachment between cellulosic surfaces, not unlike the effect of cationic flocculants. It also should be noted that polyelectrolyte complexes can be effective drystrength additives (Carr et al. 1977; Gernandt 2003; Gärdlund et al. 2003, 2005; Lofton et al. 2005). 


\section{POLYETHYLENE OXIDE (PEO) RETENTION AID SYSTEMS}

The third major class of retention aid systems that we will consider seems to contradict almost everything that has been discussed so far in this article. Polyethelene oxide is non-ionic. Therefore the system cannot rely on most of the mechanisms discussed so far, e.g. charged patches, charged anchoring sites, charge complexation, etc. In addition, PEO has little tendency to adsorb onto many of the kinds of fibers and other materials of interest to papermakers. The polymer can be difficult to dissolve in water, especially when dealing with PEO products having very high molecular mass. Studies have shown that very high molecular mass is critical to the performance of PEO as a retention aid (Pelton et al. 1980; Xiao et al. 1995a,b). Results also have been found to be dependent on temperature, mixing conditions, the time of mixing, and various other details. The system seems to perform well with mechanical pulp furnishes, but it is not well suited to lignin-free systems. Perhaps because of these issues, PEO has earned a reputation of being a "fussy" retention aid system. PEO-based systems also are said to produce relatively large fiber flocs (Polverari et al. 2001), and they are not noted for promoting faster drainage, as is often the case with cationic PAM-based retention aid systems.

The flipside is that PEO can achieve retention results in some situations that exceed what can be achieved with equivalent amounts of either cationic or anionic PAM products (Gibbs et al. 1997; Xu and Deng 1999). In particular, because PEO systems do not rely on electrical charges, they can achieve high efficiency even in systems with very high electrical conductivity and also in systems with sky-high levels of anionic colloidal matter. PEO-based retention aid systems appear to be particularly suitable for use with mechanical pulps (Pelton et al. 1980; Tay 1980, 1997; Braun and Ehms 1984; Rahman and Tay 1986; Gibbs et al. 1997; Allen et al. 1999; Allen and LaPointe 2005a,b; Laivins et al. 2001; Polverari et al. 2001; Liu et al. 2004).

\section{Brush Copolymers, etc.}

A typical PEO product is simple to describe, since the polymer is just a linear chain comprised of $-\mathrm{CH}_{2}-\mathrm{CH}_{2}-\mathrm{O}-$ repeat units. However, as a recent innovation, high retention performance also can be achieved when using a graft copolymer in which PEO side-chains are appended to a resilient, cost-effective polyacrylamide chain (Deng et al. 1994; Gibbs et al. 1997; Xiao et al. 1996a,b). Xiao et al. (1995a,b) showed that such copolymers were effective even with just 0.3 to $0.8 \%$ of ethylene glycol content, consisting of chains with at least 9 repeat ethylene oxide units. Another advantage that is attributed to the acrylamide backbone structure is that the graft copolymers showed good tolerance of hydrodynamic shear during preparation of solutions.

\section{PEO Solution Preparation}

As in the case of acrylamide-type retention aids, one of the most cost-effective ways to ship PEO is in dry bead form. Not only does delivery of dry polymer minimize costs during shipping, but it also helps to minimize shelf-life issues. Using suitable dryfeed metering equipment, adductors, and controlled mixing, dry-form retention aids can be prepared in reproducible fashion as they are needed. 
For the sake of convenience and reliability, many users of retention aids prefer to deal with retention aid formulations that are in liquid form. Burdick and Echt (1996) patented the use of an aqueous suspension of PEO. Premature dissolution of the dispersed PEO particles was inhibited by the presence of various solutes, such as citrates, in the solution phase. To dissolve the PEO, the formulation is diluted and agitated in the presence of ferric ions or free chlorine. Chung and Warrick (1994) patented a system in which PEO particles were dispersed in a mixture of glycol and glycerine.

\section{Macromolecular Entanglements}

Some hard-to-explain behavior of PEO retention aid systems appears to be related to a tendency of the macromolecular chains to become entangled in solution (Gunder and Guven 1978; Polverari and van de Ven 1996; van de Ven 1997; Kratohvil 1999; Abdallah 2002; Bednar et al. 2004). Even if one were able to prepare a perfectly dispersed solution of high-mass PEO, say by passing the solution through a suitable membrane filter, it has been shown that the polymer immediately will start to entangle again, depending on the concentration of the solution (Derek et al. 2003). Polverari and van de Ven (1996) proposed that clusters of PEO macromolecules in solution can be in a state of thermodynamic equilibrium with individually dispersed macromolecules.

It has been shown that highly entangled PEO solutions tend to be much more effective flocculants, compared to well-stirred PEO solutions, in which entanglements are mostly absent (Kratohvil et al. 1999; van de Ven et al. 2004). In particular, the cited studies showed that freshly prepared PEO solutions with gentle stirring yielded higher retention efficiencies compared to well-stirred solutions. Bednar et al. (2004) evaluated the extent of PEO entanglements by measuring the pressure drop of solution passing at a controlled rate through a capillary tube. Resistance to contraction of PEO structures at the entrance to such a capillary was found to be a very sensitive indication of entanglements. Stirring resulted in a progressive loss of entanglements. Increased storage time of the PEO solutions also was found to decrease entanglement (van de Ven et al. 2004).

\section{Helical conformations}

A possible starting point from which to explain the complex solution properties of PEO is based on a proposed helical conformation in solution (Yoshigara et al. 1964; Bedrov and Smith 2003; Bednar et al. 2004; Kobayashi and Sato 2008). In principle, such helices can be formed with the oxygen atoms directed either inward or outward, relative to the axis of the helix. Since the alternative helical structures can be expected to differ greatly with respect to water-solubility, it can be hypothesized that changes in the aspect of the helix, in response to various conditions, might activate or deactivate PEO with respect to its tendency to adsorb onto different surfaces.

\section{Cofactors}

The flocculating ability of ordinary PEO depends critically on the presence of certain phenolic or lignin-related substances in the suspension. These substances are often called cofactors (Braun and Ehms 1984; Rahman and Tay 1986; Goto and Miyanishi 2000). Phenol-formaldehyde resins (PFR) have been widely used (Xiao et al. 
1995a,b; Gibbs et al. 1997; Xu and Deng 1999; Modgi et al. 2003; Liu et al. 2004). Echt (1995) patented the use of polyhydroxystyrene in combination with PEO. Black liquor (Pelton et al. 1982; Rahman and Tay 1986) and tannic acid (Lindström and GladNordmark 1984b) also can be used as cofactors. A study by Tay (1997) showed that a wide range of materials can be used as cofactors, and it is not even necessary that the material be fully soluble in water. Ordinarily the cofactor is added first to the furnish (Triglydas et al. 2001), whereas the PEO is added very close to the headbox. Optimum ratios between the added amounts of cofactor and PEO have been reported (Lindström and Glad-Nordmark 1984a; Liu et al. 2004).

Questions remain as to why certain materials can serve as cofactors for PEO, whereas most other materials cannot. It has been proposed, for instance, that a complex forms involving hydrogen bonding between the PEO and the phenolic hydroxyl groups of the cofactor (Xiao et al. 1995b; Pelton et al. 1996). Accordingly, Liu et al. (2004) observed superior performance with a bisphenol as a cofactor. On the other hand, Xiao et al. (1999) demonstrated performance better than conventional PFR when using two kinds of cofactors that did not have any phenolic groups at all, and one of them did not even include aromatic groups.

The mechanism by which cofactors render the PEO capable of flocculating ligninfree cellulosic suspensions represents another part of the riddle. One possibility is that the cofactors are able to "flip" the sense of PEO helices (Bednar et al. 2004) so that the oxygen atoms face inwards. Figure 12 illustrates the idea that cofactors such as phenol formaldehyde resin (PFR) may cause the PEO helices to be transformed from a relatively hydrophilic form into a more hydrophobic form that would then have a high tendency to form attachments and bridges involving any nearby surfaces.

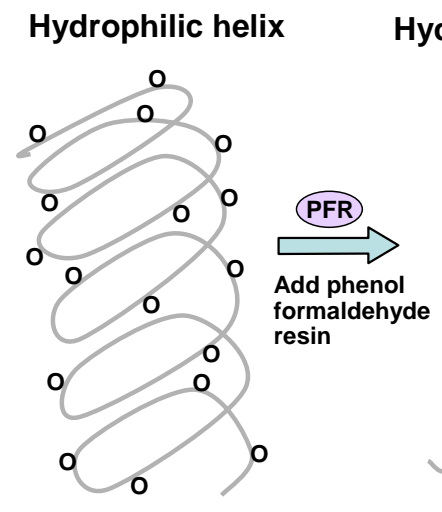

Hydrophobic helix
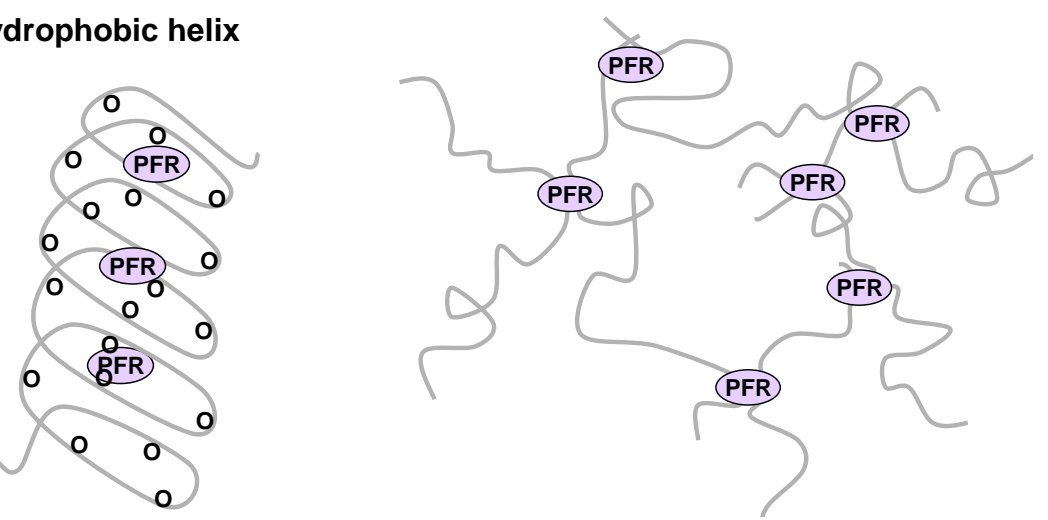

Fig. 12. A: Conceptual illustration of a possible change in the sense of a preferred helical conformation of polyethylene oxide (PEO), induced by the presence of phenol formaldehyde resin (PFR), such at the oxygen atoms face inwards and the outside of the helix is transformed into a hydrophobic state, having a strong tendency to adsorb onto nearby surfaces. B: Alternative concept in which an enhancement in the flocculating ability of PEO is mainly due to the ability of PFR to form transient multi-chain clusters of PEO

Whether or not the mechanism just described can explain the synergistic effect of PFR on the flocculating ability of ordinary PEO, it clearly does not explain all of the related observations. For instance it was found that the flocculating performance of a 
grafted brush-type PEO-PAM copolymer was actually hurt by the presence of a phenolic resin in some cases (Gibbs et al. 1997). In related studies, Xiao et al. (1995a,b) showed that PFR was effective for flocculation of latex suspensions that were prepared with a PEO-PAM copolymer grafted onto the surfaces.

\section{Network flocculation}

Another explanation that has been given for the effectiveness of cofactors is that they form a transient complex with the PEO chains in solution, creating an immense multi-chain structure (Lindström and Glad-Nordmark 1984a,b). This mechanism is illustrated in part B of Fig. 9. Such a mechanism is supported by the ability of mixtures of PEO and cofactor in the absence of fibers to form strong macroscopic gel structures, which resist breakage (Gibbs and Pelton 1999; Goto and Pelton 1999). Maximum strength of such multi-chain PEO structures was obtained at an optimum ratio of PEO and cofactor. The importance of the cofactor's identity was highlighted in the cited work, since one kind of cofactor yielded relatively stretchy gel structures, whereas another cofactor yielded gel structures having relatively little stretch before breakage.

Xiao et al (1995b) observed that addition of phenolic resin to PEO solutions yielded a momentary increase in viscosity, consistent with the formation of a transient structure involving cofactor-induced bridges between adjacent PEO chains. In the absence of fibers, such increase in solution viscosity was followed shortly by precipitation of the polymeric material from solution.

Though an originally proposed "network flocculation" mechanism (Lindström and Glad-Nordmark 1984a,b) has been shown not to be true in its entirety (van de Ven and Alince 1996), parts of the theory continue to have merit. According to the original idea, transient networks are formed by cofactor particles acting as weak crosslinking agents among PEO chains. This effect is achieved under conditions of incipient separation of the $\mathrm{PEO} /$ cofactor phase from the aqueous solution, so that rapid interaction with cellulosic surfaces is favored. As explained earlier in this article, in agitated or flowing fiber suspensions one can expect flow of aqueous solution to occur relative to the surfaces of fibers. As a consequence, high-mass polymers in solution would tend to be quickly ensnared, then drawn through the solution by the fibers as a kind of fish-net. This mechanism offers one way to account for the fact that no flocculation took place in the absence of fibers in the suspension (Lindström and Glad-Nordmark 1984a). The fishnet analogy was used to explain a greater effectiveness of the PEO system in retaining latex particles larger than $0.1 \mu \mathrm{m}$, in comparison to small latex particles, which presumably could slip through the net (Lindström and Glad-Nordmark 1984b). However, van de Ven and Alince (1996a) disproved the fish-net theory by showing a case in which relatively large calcium carbonate filler particles were not retained, whereas clay particles and latex particles were retained by PEO. Effective retention of calcium carbonate could be achieved by switching to a different cofactor (Alince et al. 1997). The tendency for PEO systems to favor retention of larger particles of filler was attributed to a hydrodynamic effect (van de Ven 1997). As discussed earlier (see also van de Ven and Mason 1981), there is a greater chance that objects having approximately the same diameter will collide with each other in the presence of flow. 
Further evidence supporting transient network formation was recently reported for another flocculant system. Transmission electron micrographs (TEM) by Nanko and Pan (2003) show networks of polyelectrolyte strands when adding certain branched cationic acrylamide flocculants to stirred fiber suspensions. The identity of the strands as cationic PAM was confirmed by the use of nanoparticles having a known negative charge. Based on the micrographs, the openings within such a network can be in the range of $50 \mathrm{~nm}$.

\section{Asymmetric bridging}

As with acrylamide-based retention aids, the word "bridging" can be justified when describing flocculation with PEO. Thus, as proposed by La Mer and Healy (1963) and Gregory (1973) for bridging systems, maximum flocculation has been observed when the addition level of PEO is enough to cover only a fraction of the accessible surface area (Rahman and Tay 1986). Also, consistent with a bridging mechanism, Pelssers et al. (1990) observed that flocculation by a PEO/cofactor combination was strongly enhanced by increasing solids concentration; this kind of effect can be explained by increasing the rate of inter-particle collisions relative to the rate at which the adsorbed polyelectrolyte chains are able to adopt flatter adsorbed conformations. Carignan et al. (1998) carried out dynamic light scattering tests and showed that more extended adsorbed conformations of PEO in TMP suspensions yielded more effective flocculation.

The term "asymmetric bridging" was coined as a means of explaining how it is possible to achieve very effective flocculation of cellulosic materials and filler particles even in cases where neither the PEO nor the cofactor alone showed significant tendency to adsorb onto the solids (van de Ven and Alince 1996; van de Ven 1997). These effects are illustrated in Fig. 13. Dynamic light scattering did not show any evidence of network formation in mixtures of PEO and PFR. In addition, softwood kraft lignin actually reduced the tendency to the PEO to remain entangled. The asymmetric bridging mechanism is one of the few explanations that has been offered to account for strong flocculation with PEO-cofactor systems, despite the inability of PEO to adsorb effectively only most chemical or mechanical pulp fibers (van de Ven 1997).
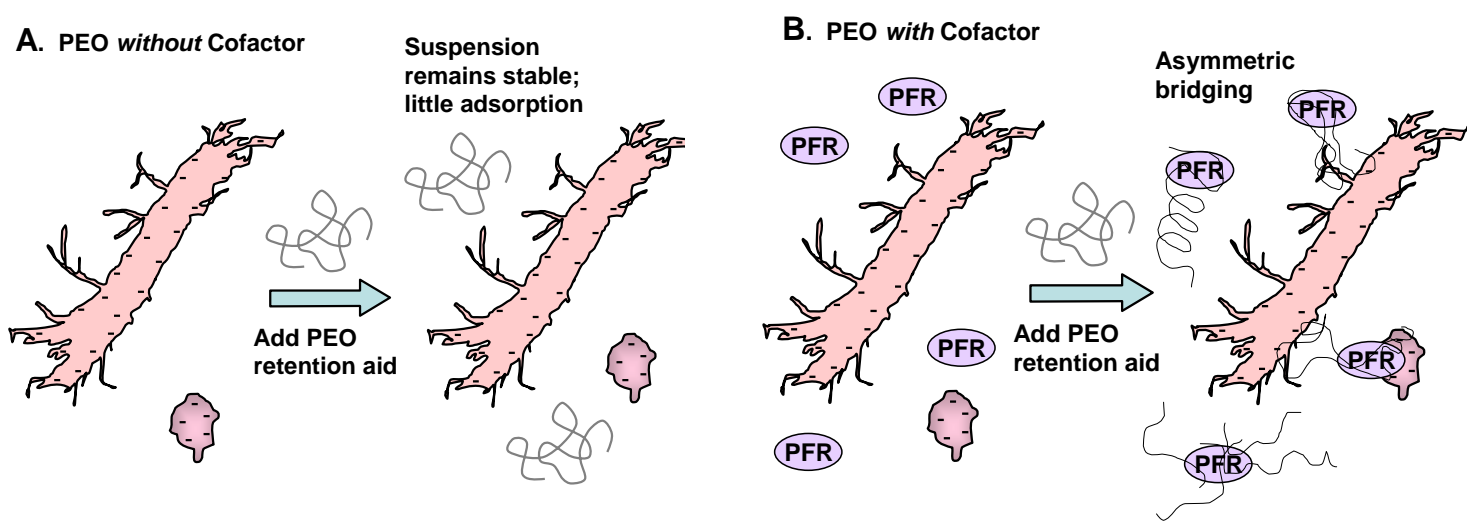

Fig. 13. Sketch of the asymmetric bridging concept of flocculation by PEO. A: As is often observed, little flocculation is expected upon addition of PEO to most kinds of fiber suspensions, and the PEO does not adsorb effectively onto the solid surfaces. B: PFR activates the PEO, possibly by stiffening the macromolecular structure, helping to form a multi-chain transient network, or affecting the conformation so that it has a favorable free energy of adsorption. 
Xiao et al. (1996a) proposed that the reason why a high molecular mass of PEO is essential in order to achieve efficient retention is that the rate of collapse of the extended adsorbed conformation needs to be slow relative to the rate at which solids collide with each other in suspension, allowing the formation of bridges. It was proposed that the role of the cofactor is to create multi-chain PEO assemblages that are large enough to be effective bridge formers. It also was proposed that cofactors may stiffen PEO structures, helping the bridge-heads to be more effective in projecting outwards into the adjacent solution in the presence of flow (van de Ven and Alince 1996a; Swerin and Ödberg 1997). Carignan et al. (1998) showed that the addition of cofactor allowed PEO to adsorb more effectively onto all of the available fiber surfaces, and also, the bridges formed by PEO in the presence of cofactors tended to be stronger. From a thermodynamic standpoint, a stiffer polyelectrolyte chain would be more likely to adsorb onto a surface, since there is less of a penalty in entropy, in comparison to the adsorption of a more flexible macromolecular segment (van de Ven and Alince 1996a). It also was proposed that adsorption of PEO onto one surface, say a mineral, can change the molecular conformation of PEO, increasing the tendency of PEO segments to bind to another surface, say cellulosic fibers.

\section{Interferences}

Although PEO systems are often quite immune to the effects of anionic colloidal matter, salts, and $\mathrm{pH}$ changes, various authors have identified substances that can interfere with PEO's retention effects. Rahman and Tay (1986) and Stacl and Dunn (1995) showed that sodium silicate, which is often used during peroxide bleaching of thermomechanical pulp, interfered with PEO. Derek et al. (2003) showed that a minor amount of chloroform would prevent clustering of PEO, which might be considered as another kind of interference to the mechanism of flocculation. van de Ven et al. (2007) observed that calcium ions formed complexes with cofactors, reducing their effectiveness. Such effects could be minimized by shortening the time between addition of the cofactor and then the PEO solution. These results are in apparent conflict with earlier results by Lapčik et al. (1995), who found that the presence of calcium chloride was beneficial for the flocculation of clay by PEO. The latter study, however, did not involve the use of a cofactor.

\section{Water System Closure}

PEO-based retention aid systems hold considerable promise for application in highly contaminated papermaking environments (Allen et al. 1999). Pelton et al. (1980) observed that the performance of PEO was actually improved by the presence of anionic colloidal matter, i.e. what usually are called "detrimental substances" with respect to the performance of other types of retention aid. PEO's performance also was independent of $\mathrm{pH}$ or alum addition, but it improved with increasing temperature. Whereas salt ions tend to hurt the performance of cPAM and aPAM retention aids (see earlier), Lindström and Glad-Nordmark (1983) showed that the PEO/cofactor system actually could be made more effective by the presence of sufficient salt concentration to reduce the distance of electrostatic repulsions between solids in a fiber suspension (see Smith-Palmer and Pelton 2002). 
Some studies have suggested beneficial effects when PEO is used in combination with highly charged cationic additives. Arledter and Mayer (1975) observed synergistic flocculation when polyethyleneiminie (PEI) was separately added to paper mill furnish that was also treated with PEO. Triglydas et al. (2001) and Modgi et al. (2003) observed that the performance of a cofactor/PEO retention aid system was improved by addition of a highly cationic starch-based coagulant to different furnishes, including thermomechanical pulp (TMP). Presumably the coagulant helped to neutralize colloidal material in the furnish, thus reducing the effective surface area of the suspended matter. The system was not effective in retaining calcium carbonate filler. An analogous system was patented that involved use of cationic additives in combination with nonionic acrylamide homopolymer of high molecular mass (Baron et al. 1990). Consistent with the idea that maybe the addition of cationic charge may help the performance of PEO, Cauley et al. (1995) patented the preparation of a cationic copolymer of ethylene oxide and related copolymers. Another approach that has been considered is the use of PEO and cPAM retention aids in the same pulp suspension (Stack and Dunn 1995; see also Baron et al. 1990).

\section{Pitch Control}

As noted by Allen and LaPointe (2005a,b), PEO-based retention aid systems can be quite effective for the retention of pitch, which may be beneficial during the production of newsprint paper. Stack and Dunn (1995) observed significant improvements in pitch removal when a cationic acrylamide retention aid was used in combination with a PEO/cofactor system. Mosbye et al. (2004) showed that PEO in the presence of certain flake-like fiber fines was able to remove wood resins from papermaking process water. Presumably the lignified surfaces on the fines were attractive to the hydrophobic pitch-like substances. Mosbye et al. (2004) showed that hemicellulosic wood components dissolved in certain papermaking fiber suspensions can inhibit PEO's interaction with wood resins. All of these approaches can be viewed as potential alternative treatment systems to be evaluated versus the usual cationic coagulants and flocculants that are used for retention of pitch in papermaking systems (Nurmi et al. 2003; Allen and LaPointe 2005a,b).

\section{LAB EVALUATION OF RETENTION AIDS}

\section{Lab Evaluations of Retention Efficiency}

Laboratory testing of retention aid polymers can be easily justified based on the costs and risks associated with full-scale trials during commercial production runs on large paper machines. Although "mill trials" may ultimately need to be carried out, it is possible to use the results of lab tests to select not only the kinds of additives most likely to be effective, but also to make an estimate of the dosage levels to be employed during such on-machine runs. In order to be useful in this respect it is important that the laboratory tests bear some resemblance to production conditions, both in terms of the chemical environment, but also in terms of hydrodynamic shear conditions. 
Details of many available laboratory tests that are useful in evaluation of retention aid dewatering chemicals, were considered in an earlier review article (Hubbe 2003), which focused on the equipment. Many of the most useful tests bear some similarity to the Dynamic Drainage/Retention Jar developed by Britt (1973a). In that test a slurry of fibers, usually having a solids content similar to what is employed just before the formation of paper, is continually stirred in a cylindrical jar that has a screen base. The speed-controlled stirring action, although it exerts non-uniform hydrodynamic shear stress to the contents of the jar, is meant to approximate the typical levels of shear stress in key parts of a paper machine system (Tam Doo et al. 1984). In the classical "Britt Jar" test (Britt 1973), the impeller runs continuously throughout the experiment, including when filtrate samples are being collected from a valve below the screen. Because any fine matter that is attached to fibers cannot pass through the screen, the results can give a measure of the effectiveness of retention aid treatments. Related lab devices and procedures often involve formation of a fiber mat, which can make the testing procedures more realistic, but often somewhat more challenging to achieve reproducible results. Other variables to be considered include whether or not vacuum is applied to assist dewatering and whether pulsations are applied in order to represent the effects of hydrofoil dewatering elements or vacuum boxes over which a forming fabric passes during the papermaking process.

\section{Flocculation Testing}

Another perspective from which to compare retention aid systems, treatment strategies, or dosages involves measurements of flocculation. Blanco et al. (1996) discussed the possibility of using online flocculation test results as a means of controlling retention aid levels. To implement such a strategy one assumes that there exists a strong relationship between flocculation extent and the desired effect, retention efficiency (Hubbe 2003, 2007). One topic that may have received insufficient attention up to this point is the simultaneous optimization of retention and flocculation. Papermakers generally strive for efficient retention, in combination with a minimization of persistent fiber flocs.

Another area of research that merits follow-up activity is in the imaging of macromolecules. Articles cited earlier in this review have helped to open up a fresh perspective regarding the actual shapes of macromolecules as they are seemingly "caught in the act" of functioning as retention aids and charge-control agents. Many questions remain, which probably could best be addressed with the help of methods that are capable of resolving the macromolecules themselves, ultimately providing some basis by which to judge between various cartoon representations of the molecules, as in the case of those that have been used to illustrate the present article. 


\section{LITERATURE CITED}

Abdallah, M. (2002). "The role of polymer entanglements in polyethylene oxide (PEO) induced fines flocculation," PhD Thesis, Dept. Chem. Eng., McGill Univ.

Adachi, Y. (1995). "Dynamic aspects of coagulation and flocculation," Adv. Colloid Interface Sci. 56, 1-31.

Adamczyk, Z., and van de Ven, T. G. M. (1981). "Deposition of Brownian particles onto cylindrical collectors,” J. Colloid Interface Sci. 84(2), 497-518.

Adamsky, F. A., and Williams, B. J. (1996). "Effects of new drainage/retention/formation technology for improving production rates and runnability of recycled fiber cylinder machines," TAPPI 1996 Papermakers Conf., TAPPI Press, Atlanta, 451-458.

Alfano, J. C., Carter, P. W., Dunham, A. J., Nowak, M. J., and Tubergen, K. R. (2000). "Polyelectrolyte-induced aggregation of microcrystalline cellulose: Reversibility and shear effects," J. Colloid Interface Sci. 223(2), 244-254.

Alince, B. (1996). "Time factor in pigment retention," TAPPI J. 79(3), 291-294.

Alince, B., Prusbska, J., and van de Ven, T. G. M. (1997). "Ground and precipitated $\mathrm{CaCO}_{3}$ deposition on fibers in the presence of PEO and kraft lignin," Paper Technology 38(2), 51-54.

Alince, B., and Robertson, A. A. (1974). "Aggregation of microcrystalline cellulose with polyethylenimine," Colloid Polymer Sci. 252(11), 920-927.

Alince, B., and van de Ven, T. G. M. (1997). "Effect of polyethylene oxide and kraft lignin on the stability of clay and its deposition on fibers," TAPPI J. 80(8), 181-186.

Alince, B., and van de Ven, T. G. M. (1997). "Porosity of swollen pulp fibers evaluated by polymer adsorption," in C. F. Baker, ed., The Fundamentals of Papermaking Materials, Pira Intl., Leatherhead, Surrey, UK, 771-788.

Allen, L. H., and LaPointe, C. L. (2005a). "Effectiveness of retention aids for pitch control in TMP newsprint manufacture. Part 1: Low shear," Pulp Paper Can. 106(12), 102-107.

Allen, L. H., and LaPointe, C. L. (2005b). "Effectiveness of retention aids for pitch control in TMP newsprint manufacture. Part II: High shear," Pulp Paper Can. 106(12), 108-113.

Allen, L., and Polverari, M. (2000). "Dendrimers: A new retention aid for newsprint, mechanical printing grades, and board," Nordic Pulp Paper Res. J. 15(5), 407-415.

Allen, L., Polverari, M., Levesque, B., and Rancis, W. (1999). "Effects of system closure on retention and drainage aid performance in TMP newsprint manufacture," TAPPI J. 82(4), 188-195.

Andersson, K. and Lindgren, E. (1996). "Important properties of colloidal silica in microparticulate systems," Nordic Pulp Paper Res. J. 11(1), 15-21, 57.

Arledter, H. F., and Mayer, A. (1975). "Synergistic flocculation of fiber-containing suspensions of the pulp and paper industry," Das Papier 29(10A), V32-V43.

Ariel, G., and Andelman, D. (2003). "Persistence length of a strongly charged rodlike polyelectrolyte in the presence of salt," Physical Rev. E 67, 011805, 1-11.

Arno, J. N., Frankle, W. R., and Sheridan, J. L. (1974). "Zeta potential and its application to filler retention," Tappi 57(12), 97-100. 
Åsselman, T., and Garnier, G. (2001). "Polymer transfer during fines detachment under turbulent flow: Mechanisms and implications," J. Pulp Paper Sci. 27(2), 60-65.

Baron, J. J., Nowakowski, T., Farrington, T. A., and Mahn, F. R. (1990). "Retention and/or drainage aid," U. S. Pat. 4,894,119.

Beck, U., Müller, F., Goossens, J. W. S., Rohloff, E., and Tretter, H. (1977). "Theoretical and practical contributions to the elucidation of retention problems," Wochenbl. Papierfabr. 105(11/12), 391-398.

Bednar, F., de Oliveira, M. H., van de Ven, T. G. M., and Paris, J. (2004). "Monitoring of poly(ethylene oxide) entanglement," PAPTAC 90th Annual Meeting, A91-A96.

Bedrov, D., and Smith, G. D. (2003). "The role of local conformations in the stretching of a poly(ethylene oxide) chain in solution," J. Chem. Phys. 118(14), 6656-6663.

Beer, M., Schmidt, M., and Muthukumar, M. (1997). "The electrostatic expansion of linear polyelectrolytes: Effects of gegenions, co-ions, and hydrophobicity," Macromol. 30(26), 8375-8385.

Beghello, L., and Eklund, D. (1999). "The influence of the chemical environment on fiber flocculation," J. Pulp Paper Sci. 25(7), 246-250.

Bhardwaj, N. K., Kumar, S., and Bajpai, P. K. (2005). "Effect of zeta potential on retention and drainage of secondary fibers," Colloids Surf. A 260(1-3), 245-250.

Blanco, A., Negro, C., Hooimeijer, A., and Tijero, J. (1996). "Polymer optimization in paper mills by means of a particle size analyser: An alternative to zeta potential measurements," Appita 49(2), 113-116.

Bøhmer, E. (1981). "Filling and loading," in: Pulp and Paper Chemistry and Chemical Technology, $3^{\text {rd }}$ Ed., Casey, J. P. (ed.), Wiley, New York, Vol. 3, Ch. 15, 1515-1546.

Braun, D. B., and Ehms, D. A. (1984). "Filler and fiber retention in newsprint and groundwood specialties using poly(ethylene oxide," Tappi J. 67(9), 110-114.

Brenner, H. (1968). "The slow motion of a sphere through a viscous fluid towards a plane surface," Chem. Eng. Sci. 16(3-4), 242-251.

Britt, K. W. (1973a). "Retention of additives during sheet formation," Tappi 56(3), 83-86.

Britt, K. W. (1973b). "Mechanisms of retention during paper formation," Tappi 56(10), 4650.

Britt, K. W. (1981). "Paper sheet formation: Observations concerning retention," Tappi 64(5), 53-55.

Britt, K. W., and Unbehend, J. E. (1976a). "New methods of monitoring retention," Tappi 59(2), 67-70.

Britt, K. W., and Unbehend, J. E. (1976b). "Electrophoresis in paper stock suspensions measured by mass transport analysis," Tappi 57(12), 81-84.

Britt, K. W., and Unbehend, J. (1985). "Water removal during paper formation," Tappi J. 68(4), 104-107 (1985).

Buchhammer, H.-M., Petzold, G., and Lunkwitz, K. (1993). "The interaction between oppositely charge polyelectrolytes in the presence of solid surfaces," Colloids Surf. A 76, 81-85.

Buchhammer, H.-M., Kramer, G., and Lunkwitz, K. (1994). "Interaction of colloidal dispersions of non-stoichiometric polyelectrolyte complexes and silica particles," Colloids Surf. A 95, 299-304. 
Buontempo, J. T. (1996). "The effects of salts on the performance of cationic flocculants used as retention aids for alkaline fine paper," TAPPI 1996 Papermakers Conf., TAPPI Press, Atlanta, 49-57.

Burdick, C. L., and Echt, E. (1996). "Aqueous suspensions of poly(ethylene oxide) useful as retention aids in paper manufacture," U. S. Patent 5,578,168.

Burgess, M. S., Phipps, J. S., and Xiao, H. (2000). "Flocculation of PCC induced by polymer/microparticle systems: Floc characteristics," Nordic Pulp Paper Res. J. 15(5), 572-578.

Carignan, A., Garnier, G., and van de Ven, T. G. M. (1998). "The flocculation of fines by PEO/cofactor retention aid system," J. Pulp Paper Sci. 24(3), 94-99.

Carlson, U. (1990). "Some aspects of microparticle flocculation," Proc. EUCEPA XXIV: The World Pulp and Paper Week, Paper Technol., Stockholm, 161-171.

Carr, M. E., Hamerstrand, G. E., Hofreiter, B. T., and Russell, C. R. (1977). “A polysalt complex for wet-end addition," Tappi 60(12), 148-149.

Cauley, T. A., Langley, J. G., and Nixon, A. (1995). "Manufacture of paper using retention aids," PCT Int. Appl. WO 95 02,088.

Chang, M. Y., and Robertson, A. A. (1967). "Flocculation studies of fiber suspensions: Influence of zeta potential," Pulp Paper Mag. Can. 68(9), T438-T444.

Chang, S. Y., Ring, T. A., and Trujillo, E. M. (1991). "Coagulation kinetics of amorphous colloidal silica suspensions with and without hydroxypropyl cellulose polymer," Colloid Polymer Sci. 269(8), 843-849.

Chi, H., Li, H., Liu, W., and Zhan, H. (2007). "The retention- and drainage-aid behavior of quaternary chitosan in papermaking system," Colloids Surf. A 297, 147-153.

Cho, B.-U., Garnier, G., van de Ven, T. G. M., and Perrier, M. (2006). "A bridging model for the effects of a dual component flocculation system on the strength of fiber contacts in flocs of pulp fibers: Implications for control of paper uniformity," Colloids Surf. A 287, 117-125.

Chung, D. K. (1991). "Retention and drainage aid for alkaline fine papermaking process," U. S. Pat. 5,126,014.

Chung, D. K., and Warrick, B. (1994). "Liquid suspension of polyethylene oxide for use in treating paper and pulp wastewater," U. S. Patent 5,342,538.

Claesson, P. M., Poptoshev, E., Blomberg, E., and Dedinaite, A. (2005). "Polyelectrolytemediated surface interactions," Adv. Colloid Interface Sci. 114, 173-187.

Dahlgren, M. A. G., and Leermakers, F. A. M. (1995). "Depletion zones in polyelectrolyte systems - polydispersity effects and colloidal stability," Langmuir 11(8), 2996-3006.

Das, B. S., and Lomas, H. (1973). "Flocculation of paper fines. I. Adsorption of and flocculation by polyelectrolytes. II. Study of the nature of the solid surface and soluble impurities," Pulp Paper Mag. Can. 74(8), 95-100.

Davison, R. W. (1983). "Mechanism of fine-particle retention in paper," Tappi J. 66(11), 69-72.

Deng, Y., Pelton, R., Xiao, H., and Hamielec, A. (1994). "Synthesis of nonionic flocculants by gamma irradiation of mixtures of polyacrylamide and poly(ethylene oxide)," J. Appl. Polymer Sci. 54, 805-813. 
Dennis, G. L., and Ellms, C. W. (1982). "Retention aids are important in the retention of calcium carbonate," TAPPI 1982 Papermakers Conf., TAPPI Press, Atlanta, 69-72.

Derek, L. H., Boualem, H., and Steven, R. K. (2003). "Clustering of poly(ethylene oxide) in water revisited," J. Polymer Sci.: Part B: Polymer Physics 41, 135-138.

Dickinson, E., and Eriksson, L. (1991). "Particle flocculation by adsorbing polymers," Adv. Colloid Interface Sci. 34, 1-29.

Dong, Y.-F., and Liu, W.-X. (2006). "Modification of bentonite and its microparticiulate retention effect on secondary fibers," China Pulp Paper 25(12), 19-22.

Dunham, A. J., Sherman, L. M., and Alfano, J. C. (2002). "Effect of dissolved and colloidal substances on drainage properties of mechanical pulp suspensions," J. Pulp Paper Sci. 28(9), 298-304.

Dunham, A. J., Tubergen, K. R., Govoni, S. T., and Alfano, J. C. (2000). "The effect of dissolved and colloidal substances on flocculation of mechanical pulps," J. Pulp Paper Sci. 26(3), 95-101.

Durand-Piana, G., Lafuma, F., and Audebert, R. (1987). "Flocculation and adsorption properties of cationic polyelectrolytes toward Na-montmorillonite dilute suspensions," J. Colloid Interface Sci. 119(2), 474-480.

Duval, M., and Boue, F. (2007). "Dilute poly(ethylene oxide) aqueous solutions in a turbulent flow," Macromolecules 40(23), 8384-8388.

Echt, E. (1995). "Phenolic compound/polyethylene oxide retention system," U. S. Patent $5,472,570$.

Eklund, D., and Lindström, T. (1991). Paper Chemistry - An Introduction, DT Paper Science Publ., GRankulla, Finland.

Eisenberg, H. (1976). Biological Macromolecules and Polyelectrolytes in Solution, Clarendon Press, Oxford.

Eriksson, L., and Alm, B. (1993). "Effects of polyelectrolyte characteristics and flocculation conditions on fine particle floc properties," Nordic Pulp Paper Res. J. $8(1), 153-175$.

Erspamer, A. (1940). “The flocculation and dispersion of papermaking fibers," Paper Trade J. 110(June 13), 33-38.

Fallon, T. C. (1992). "Papermaking process with improved retention and maintained formation," U. S. Pat. 5,571,380.

Farley, C. E. (1997). "Factors influencing the rate of charge decay," Tappi J. 80(10), 177183.

Feng, J., Wei, X., Opalka, A., Pelzer, R., and Schulte, J. (2001). "A new generation of solution retention and dewatering aids," Wochenbl. Papeierfabr. 129(1-2), 32-34.

Feng, X. H., Pelton, R., Leduc, M., and Champ, S. (2007a). "Colloidal complexes from poly(vinyl amine) and carboxymethyl cellulose mixtures," Langmuir 23(6), 29702976.

Feng, X., Pouw, K., Leung, V., and Pelton, R. (2007b). “Adhesion of colloidal polyelectrolyte complexes to wet cellulose,” Biomacromol. 8(7), 2161-2166.

Fleer, G. J., Cohen-Stuart, M. A., Scheutjens, J. M. H. M., Cosgrove, T., and Vincent, B. (eds). (1993). Polymers at Interfaces, Chapman and Hall, London, see 343-375. 
Fleer, G. J., and Lyklema, J. (1974). "Polymer adsorption and its effect on the stability of hydrophobic colloids. III. Kinetics of the flocculation of silver iodide solds," $J$. Colloid Interface Sci. 55(1), 228-238.

Forsberg, S., and Ström, G. (1994). "The effect of contact time between cationic polymers and furnish on retention and drainage," J. Pulp Paper Sci. 20(3), J71-J76.

Fowler, A. (1977). "Benefits of dual retention aid systems," Paper 187(3), 122,137.

Fu, Y.-J., Shi, S.-I., Qiu, H.-Y., and Qin, M.-H. (2007). "Retention and drainage performance of star-shape cationic polyacrylamide," China Pulp Paper 26(4), 19-23.

Gaiolas, C., Silva, M. S., Costa, A. P., and Belgacem, M. N. (2006). "Influence of the combined use of cationic starch and cationic polyacrylamide on the quality of printing paper," TAPPI J. 5(5), 3-8.

Gärdlund, L., Forsström, J., Andreasson, B., and Wågbberg, L. (2005). "Influence of polyelectrolyte complexes on the strength properties of papers from unbleached kraft pulps with different yields," Nordic Pulp Paper Res. J. 20(1), 71-77.

Gärdlund, L., Wågbberg, L., and Gernandt, R. (2003). "Polyelectrolyte complexes for surface modification of wood fibers. 2. Influence of complexes on wet and dry strength of paper," Colloids Surf. A 218(1-3), 137-149.

Gernandt, R., Wågberg, L., Gärdlund, L., and Dauzenberg, H. (2003). "Polyelectrolyte complexes for surface modification of wood fibers. 1. Preparation and characterization of complexes for dry and wet strength improvement of paper," Colloids Surf. A 213(1), 15-25.

Gibbs, A., and Pelton, R. (1999). "Effect of PEO molecular weight on the flocculation and resultant floc properties of polymer-induced PCC flocs," J. Pulp Paper Sci. 25(7), 267-271.

Gibbs, A., Xiao, H., Deng, Y., and Pelton, R. (1997). "Flocculants for precipitated calcium carbonate in newsprint pulps," Tappi J. 80(4), 163-170.

Gill, R. I. S., and Herrington, T. M. (1987). "The effect of surface charge on the flocculation of kaolin suspensions with cationic polyacrylamides of varying molar mass but similar cationic character," Colloids Surf. 25, 297-310.

Goossens, J. W. S., and Luner, P. (1976). "Flocculation of microcrystalline cellulose suspensions with cationic polymers - Effect of agitation," Tappi 59(2), 89-94.

Goto, S., and Miyanishi, T. (2000). "Novel cofactors/PEO flocculation systems for colloidal suspensions," Nordic Pulp Paper Res. J. 15(5), 395-399.

Goto, S., and Pelton, R. (1999). "The influence of phenolic cofactors on the properties of calcium carbonate flocs formed with PEO," Colloids Surf. 155, 231-239.

Gregory, J. (1973). "Rates of flocculation of latex particles by cationic polymers," $J$. Colloid Interface Sci. 42(2), 448-456.

Gruber, E., Grossmann, K., and Schempp, W. (1996a). "Interactions of synthetic cationic polymers with fibers and fillers. Pt. 1: Influence on adsorption," Wochenbl. Papierfabr. 124(1), 4-11.

Gruber, E., Grossmann, K., and Schempp, W. (1996b). "Interactions of synthetic cationic polymers with fibers and fillers. Part 2: Effects on dewatering and retention," Wochenbl. Papierfabr. 124(3), 102-105.

Gruber, E., and Müller, P. (2001). "Investigations of the flocculation behavior of microparticle retention systems," TAPPI Papermakers Conf., TAPPI Press, Atlanta. 
Gunder, A., and Guven, O. (1978). "Molecular association in aqueous solutions of high molecular weight poly(ethylene oxide," Makromol. Chem. 179, 2789-2791.

Hansson, T. E. A., and Jachimowicz, F. (1984). "Retention and drainage aid," U. S. Pat. $4,565,604$.

Hansson, T. E. A., and Jachimowicz, F. (1985). "Retention and drainage aid," U. S. Pat. $4,513,122$.

Harrington, J. C., and Schuster, M. A. (1996). "Method for improving retention and drainage characteristics in alkaline papermaking," U. S. Pat. 5,482,595.

Hedborg, F., and Lindström, T. (1996). "Some asepcts on the reversibility of flocculation of paper stocks," Nordic Pulp Paper Res. J. 11(4), 254-259.

Henderson, J. M., and Wheatley, A. D. (1987). "Factors affecting a loss of flocculation activity of polyacrylamide solutions: Shear degradation, cation complexation, and solution aging," J. Appl. Polymer Sci. 333, 669-684.

Hogg, R. (1999). "The role of polymer adsorption kinetics in flocculation," Colloids Surf. A 146, 253-263.

Holmberg, M., Wigren, R., Erlandsson, R., and Claesson, P. M. (1997). "Interactions between cellulose and colloidal silica in the presence of polyelectrolytes," Colloids Surf. A 129-130, 175-183.

Honig, D. S., Farinato, R. S., and Jackson, L. A. (2000). "Design and development of the micropolymer system: An "organic microparticle" retention/drainage system," Nordic Pulp Paper Res. J. 15(5), 536-544.

Horn, D., and Linhart, F. (1996). "Retention aids," in: Paper Chemistry, Roberts, J. C. (ed.), Second Ed., Blackie Academic and Professional, Chapman and Hall, Glasgow, 64-82.

Horn, D., and Melzer, J. (1975). "The effect of high molecular cationic dewatering aids on the electrokinetic properties of pulp," Papier 29(12), 534-541.

Horn, D., and Melzer, J. (1977). "Electrostatic and steric effects of cationic polymers adsorbed on cellulose," Trans BPBIF Symp. Fiber-Water Interactions in Papermaking (Oxford), 135-150.

Hostetler, R. E.., and Swanson, J. W. (1974). "Diffusion into and adsorption of polyethylenimine on porous silica gel," J. Polymer Sci. 12(1), 29-43.

Hubbe, M. A. (1987). "Detachment of colloidal hydrous oxide spheres from flat solids exposed to flow. 4. Effects of polyelectrolytes," Colloids Surf. 25, 325-339.

Hubbe, M. A. (2000b). "Reversibility of polymer-induced fiber flocculation by shear. 1." Nordic Pulp and Paper Res. J. 15(5), 545-553; 16(4), 375.

Hubbe, M. A. (2001). "Reversibility of polymer-induced fiber flocculation by shear. 2." Nordic Pulp and Paper Res. J. 16(4), 369-375.

Hubbe, M. A. (2003). "Selecting laboratory tests to predict effectiveness of retention and drainage aid programs," Paper Technol. 44(8), 20-34.

Hubbe, M. A. (2004). "Filler particle shape vs. paper properties - A review," Proc. Spring Tech. Conf., TAPPI Press, Atlanta.

Hubbe, M. A. (2005). "Microparticle programs for drainage and retention," in Rodriguez, J. M. (ed.), Micro and Nanoparticles in Papermaking, TAPPI Press, Atlanta, Chapter $1,1-36$. 
Hubbe, M. A. (2006). "Bonding between cellulosic fibers in the absence and presence of dry-strength agents - A review," BioRes. 1(2), 281-318.

Hubbe, M. A. (2007). "Flocculation and redispersion of cellulosic fiber suspensions: A review of effects of hydrodynamic shear and polyelectrolytes," BioRes. 2(2), 296331.

Hubbe, M. A., Chen, H., and Heitmann, J. A. (2009). "Permeability reduction phenomena in packed beds, fiber mats, and wet webs of paper exposed to flow of liquids and suspensions: A review," BioRes. 4(1), 405-451.

Hubbe, M. A., and Heitmann, J. A. (2007). "Review of factors affecting the release of water from cellulosic fibers during paper manufacture," BioRes. 2(3), 500-533.

Hubbe, M. A., Rojas, O. J., Lucia, L. A., and Jung, T. M. (2007a). "Consequences of the nanoporosity of cellulosic fibers on their streaming potential and their interactions with cationic polyelectrolytes," Cellulose 14(6), 655-671.

Hubbe, M. A., Rojas, O. J., Lucia, L., A., and Sain, M. (2008). “Cellulosic nanocomposites: A review," BioRes. 3(3), 929-980.

Hubbe, M. A., and Wang, F. (2002). "Where to add retention aid: Issues of time and shear," TAPPI J. 1(1), 28-33.

Ibrahem, A. A., Nada, A. M. A., El-Saied, H., and El-Ashmawy, A. E. (2005). "Polyacrylamide as a filler retention aid for bagasse paper pulp," Ang. Makromol. Chem. 127, 89-102.

Janex, M. L., Chaplain, V., Counord, J. L., and Audebert, R. (1997). "Influence of adsorbed polymers on the removal of mineral particles from a planar surface," Colloid Polymer Sci. 275, 352-363.

Jaycock, M. J., and Swales, D. K. (1994). “The theory of retention,” Paper Technol. 35(8), 26-33.

Jokinen, O., and Palonen, H. (1986). "Interdependence of retention and formation in the manufacture of SC paper," Paperi Puu 68(11), 801-802, 805-808.

Jönsson, B., Lindman, B., Holmberg, K., and Kronberg, B. (1998). Surfactants and Polymers in Aqueous Solution, Wiley, New York.

Kamijo, Y., and Miyanishi, T. (2002). "Retention aid chemicals for high speed paper machines," Japan Tappi J. 56(6), 110-119.

Kamiti, M., and van de Ven, T. G. M. (1995). "Impinging jet studies of the kinetics of deposition and dissolution of calcium-carbonate particles," Colloids Surf. A 100, 117 129.

Kasper, D. R. (1971). Theoretical and Experimental Investigations of the Flocculation of Charged particles in Aqueous Solutions by Polyelectrolytes of Opposite Charge, Ph.D. Diss., CIT, Pasadena, CA, 201 pp.

Kekkonen, J., Lattu, H., and Stenius, P. (2001). "Adsorption kinetics of complexes formed by oppositely charged polyelectrolytes," J. Colloid Interface Sci. 234(2), 384392.

Koethe, J. L., and Scott, W. E. (1993). "Polyelectrolyte interactions with papermaking fibers: the mechanism of surface-charge decay," Tappi J. 76(12), 123-133.

Kobayashi, M., and Sato, H. (2008). "Conformational analysis of ethylene oxide and ethylene imine oligomers by quantum chemical calculation," Polymer J. 40(4), 343349. 
Kratohvil, D., Alince, B., and van de Ven, T. G. M. (1999). "Flocculation of clay particles with poorly and well-dissolved polyethylene oxide," J. Pulp Paper Sci. 25(9), 331-335.

Kuo, L. L., Leung, R. Y., and Williams, K. S. (1995). "Water-soluble cationic copolymers and their use as drainage retention aids in papermaking processes," $U$. $S$. Pat. 5,473,033.

Laivins, G., Polverari, M., and Allen, L. (2001). "Performance of poly(ethylene oxide)/ cofactor retention aids in mechanical pulp furnishes," TAPPI J. 84(3), 57 (digital).

La Mer, V. K., and Healy, T. W. (1963). "Adsorption-flocculation reactions of macromolecules at the solid-liquid interface," Rev. Pure Appl. Chem. 13(suppl.), 112-133.

Lamminen, P., Koponen, A., Hounni, J., Leino, T., and Laakonen, K. (2005). "Investigation of a new type of retention aid mixer," Paperi Puu 87(8), 512-516.

Lapčik, L., Alince, B., and van de Ven, T. G. M. (1995). "Effect of poly(ethylene oxide) on the stability and flocculation of clay dispersions," J. Pulp Paper Sci. 21(1), J19$\mathrm{J} 24$.

Lindström, T., and Glad-Nordmark, G. (1983). "Selective adsorption, flocculation, and fractionation of wood pulps with polyethyleneoxide," J. Colloid Interface Sci. 94(2), 404-411.

Lindström, T., and Glad-Nordmark, G. (1984a). "Network flocculation and fractionation of latex particles by means of a polyehtyleneoxide-phenolformaldehyde resin complex," J. Colloid Interface Sci. 97(1), 62-67.

Lindström, T., and Glad-Nordmark, G. (1984b). "Flocculation of latex and cellulose dispersions by means of transient polymer networks," Colloids Surf. 8(4), 337-351.

Lindström, T., and Söremark, C. (1976). "Adsorption of cationic polyacrylamides on cellulose," J. Colloid Interface Sci. 55(2), 305-312.

Lindström, T., Söremark, C., and Eklund, L. (1976). "Kinetic aspects of the flocculation of cellulosic fibre dispersions with polyacrylamides," Tech. Trans. CPPA 3(4), TR114-TR118.

Lindström, T., Söremark, C., Heinegård, C., and Martin-Löf, S. (1974). "The importance of electrokinetic properties of wood fiber for papermaking," Tappi 57(12), 94-96.

Lindström, T., and Wågberg, L. (1983). "Effects of pH and electrolyte concentration on the adsorption of cationic polyacrylamides on cellulose," Tappi J. 66(6), 83-85.

Liu, J. (2005). "Papermaking technology evolution: Its impact on wet-end retention," Paper Technol. 46(8), 31-36.

Liu, Q., Zhan, H., He, B., Liu, J., Pan, Z., and Zhang, F. (2004). “Application of $\mathrm{PEO} /$ cofactor retention system in ONP/OMG deinked pulp making newsprint," ISTP 353-356.

Lofton, M. C., Moore, S. M., Hubbe, M. A., and Lee, S. Y. (2005). "Polyelectrolyte complex desposition as a mechanism of paper dry-strength development," Tappi $J$. 4(9), 3-7.

London, F. (1930). "Properties and applications of molecular forces," Z. Phys. Chem. B11, 222-251.

Lu, S., Liu, R., and Sun, X. (2001). "A study of the synthesis and application of an inverse emulsion of amphoteric polyacrylamide as a retention aid in papermaking," $J$. Appl. Polymer Sci. 84, 343-350. 
Maltesh, C., and Shing, J. B. W. (1998). "Effects of water chemistry on flocculant makedown and subsequent retention \& drainage performance," 1998 International Environmental Conference and Exhibit, TAPPI Press, Atlanta, 227-234.

Matula, J. (2006). "New efficient mixing system of papermaking additives cuts fresh water consumption," Papermakers Conf., TAPPI Press, Altanta, Paper 7-2.

Maury, E. E., Buelte, R., and Johnson, C. C. (1998). "Higher actives dispersion polymer to aid clarification, dewatering, and retention and drainage," U. S. Pat. 6,171,505.

McKenzie, A. W. (1968). "Structure and properties of paper. XVIII. The retention of wetend additives," Appita 21(4), 104-116.

McNeal, M. R., Nanko, H., and Hubbe, M. A. (2005). "Imaging of macromolecular events occurring during the manufacture of paper," $13^{\text {th }}$ Fundamental Research Symposium, Cambridge, Sept. 2005, 1225-1267.

Mei, Y., Abetz, C., Birkert, O., Schädler, V., Leyrer, R. J., and Ballauff, M. (2006). "Interaction of spherical polyelectrolyte brushes with calcium carbonate and cellulose fibers: Mechanistic studies and their application in papermaking," J. Appl. Polymer Sci. 102, 233-241.

Miller, C. E., and Stratton, R. A. (1990). "Effects of polymer partitioning on fines retention," TAPPI Papermakers Conf. Proc., TAPPI Press, Atlanta, 329-342.

Miyanishi, T., and Montegi, S. (1996). "Optimization of flocculation and drainage for microparticle systems by zeta potential control," Proc. 1996 Papermakers Conf., TAPPI Press, Atlanta, 73-82.

Modgi, S. B., Thorburn, I., and Englezos, P. (2003). "Retention of pretreated calcium carbonate with a PEO/cofactor/fixative system," TAPPI Spring Technical Conf. and Trade Fair, TAPPI Press, Atlanta, digital document.

Moore, E. E. (1976). "Charge relationiships of dual polymer retention aids," Tappi 59(6), 120-122.

Mosbye, J., Moe, S., Tammelin, T., Saarinen, T., and Laine, J. (2004). "The ability of PEO to remove model colloidal extractives from solutions with different types of fines," Nordic Pulp Paper Res. J. 19(1), 59-66.

Mühle, K. (1985). "Particle adhesion in coagulation and bridging flocculation," Colloid Polymer Sci. 263, 660-672.

Mühle, K. (1987). "The effect of mechanical forces on adhesive strength in bridging flocculation," Colloids Surf. 22(2-4), 249-269.

Müller, F., and Beck, U. (1978). "Dual product systems for retention and dewatering in the paper industry," Das Papier 32(10A), V25-V31.

Nanko, H., McNeal, M., and Pan, S. (2006). "Understanding wet-end polymer performance through visualization of macromolecular events by transmission electron microscopy," Pan Pacific Conf. - Advances in Pulp \& Paper Sciences and Technologies, Seoul, Korea, 1-18.

Nanko, H., and Pan, S. (2003). "Visualization of polymer adsorption on pulp fiber. 1. Polyacrylamide," 2003 TAPPI Spring Technical Conference and Trade Fair, digital document.

Nässman, J., Lindholm, J., and Ekund, D. (1998). "The influence of cationic retention aids on the flocculation of thermomechanical pulp," PTS Symp: Chemical Technology of Papermaking, PTS, 23, 1-8. 
Nedelcheva, M. P., and Stoilkow, G. V. (1977). "Polyacrylamide adsorption by cellulose," Colloid Polymer Sci. 255, 327-333.

Nelson, J. A. (1978). "Retention aid performance. Effects of process variables," Tappi 61(11), 108-110.

Nguyen, T. Q., and Kausch, H.-H. (1992). "Chain extension and degradation in convergent flow," Polymer 33(12), 2611-2621.

Nurmi, M., Wallin, S., and Eklund, D. (2003). "Interactions between cationic polyacrylamide and TMP," Wochenbl. Papierfabr. 131(11-12), 678-682.

Nurmi, M., Westerholm, M., and Eklund, D. (2004). "Factors influencing flocculation of dissolved and colloidal substances in a thermomechanical pulp water," J. Pulp Paper Sci. 30(2), 41-44.

Ödberg, L., Tanaka, H., and Swerin, A. (1993). "Kinetic aspects of the adsorption of polymers on cellulosic fibres," Nordic Pulp Paper Res. J. 8(1), 6-9, 47.

Österberg, M. (2000). "The effect of a cationic polyelectrolyte on the forces between two cellulose surfaces and between one cellulose and one mineral surface," J. Colloid Interface Sci. 229(2), 620-627.

Pelssers, E. G. M., Cohen Stuart, M. A., and Fleer, G. J. (1990). "Kinetics of bridging flocculation - Role of relaxations in the polymer layer," J. Chem. Soc. Faraday Trans. I 86(9), 1355-1361.

Pelton, R. (1993). "A model of the external surface of wood pulp fibers," Nordic Pulp Paper Res. J. 8(1), 113-119.

Pelton, R. H., and Allen, L. H. (1984). "Factors influencing the adhesion of polystyrene spheres attached to Pyrex by polyethyleneimine in aqueous solution," J. Colloid Interface Sci. 99(2), 387-398.

Pelton, R. H., Allen, L. H., and Nugent, H. M. (1980). "Factors affecting the effectiveness of some retention aids in newsprint pulp," Svensk Papperstidning 83(9), 251-258.

Pelton, R. H., Allen, L. H., and Nugent, H. M. (1982). “Additives of increased retention and pitch control in paper manufacture," US Pat. 4,313,790.

Pelton, R., Xiao, H., Brook, M. A., and Hamielec, A. (1996). "Flocculation of polystyrene latex with mixtures of poly(p-vinylphenol) and poly(ethylene oxide)," Langmuir 12(24), 5756-5762.

Pelzer, R. (2008). "Polyacrylamides (PAM) as retention aids," in Chemical Additives for the Production of Pulp and Paper, Zellcheming Technical Committee "Chemical Additives (CHAD)," Deutscher Fachverlag, Ch. 7.3, 139-151.

Perkins, T. T., Smith, D. E., and Chu, S. (1997). "Single polymer dynamics in an elongational flow," Science 276(5321), 2016-2021.

Petäjä, T. (1980). "Fundamental mechanisms of retention with retention agents. Part 1. Electrolyte and simple polymer systems. Part 2. Dual polymer systems," Kemia Kemi 7(3), 110-112, 129-130; 7(5), 261-263.

Petlicki, J., and van de Ven, T. G. M. (1994). "Adsorption of polyethylenimine onto cellulose fibers," Colloids Surf. A 83(1), 9-23.

Petzold, G., Buchhammer, H.-M., and Lunkwitz, K. (1996). "The use of oppositely charged polyelectrolytes as flocculants and retention aids," Colloids Surf. A 119(1), 87-92. 
Petzold, G., Nebel, A., Buchhammer, H.-M., and Lunkwitz, K. (1998). "Preparation and characterization of different polyelectrolyte complexes and their application as flocculants," Colloid Polymer Sci. 276, 125-130.

Pfau, A., Schrepp, W., and Horn, D. (1999). "Detection of a single molecule adsorption structure of poly(ethylenimine) macromolecules by AFM," Langmuir 15(9), 32193225 (1999).

Pietschker, D. A., Ormerod, D. L., and Brown, C. R. (1993). "Changes in PM furnish put demand on retention/drainage chemistry," Pulp Paper 67(4), 55-58.

Polverari, M., Allen, L., and Sitholé, B. (2001). "Effects of system closure on retention and drainage aid performance in TMP newsprint manufacture. Part II," TAPPI J. 84(3), 56.

Polverari, M., and van de Ven, T. G. M. (1996). "Dilute aqueous poly(ethylene oxide) solutions: Clusters and single molecules in thermodynamic equilibrium," J. Phys. Chem. 100, 13687-13695.

Porubská, J., Alince, B., and van de Ven, T. G. M. (2002). "Homo- and heteroflocculation of papermaking fines and fillers," Colloids Surf. A 210, 223-230.

Rahman, L., and Tay, C. H. (1986). "Mechanisms of fines retention by polyethylene oxide in newsprint furnishes. Effect of stock variation," Tappi J. 69(4), 100-105.

Räisänen, K., Karrila, S., and Paulapuro, H. (1994). "The effects of retention aids, drainage conditions and pretreatment of slurry on high vacuum dewatering: A laboratory study," TAPPI 1994 Papermakers Conf., 463-473.

Richardson, P. F., and St. John, M. R. (2003). "Use of PAC in conjunction with polymers as a retention aid," TAPPI Spring Technical Conf., TAPPI Press, Atlanta, digital document.

Roberts, J. C., Au, C. O., Clay, G. A., and Lough, C. (1986). "The effect of C ${ }^{14}$-labelled cationic and native starches on dry strength and formation," Tappi J. 69(10), 88-93.

Rojas, O. J., Claesson, P. M., Muller, D., and Neuman, R. D. (1998). "The effect of salt concentration on adsorption of low-charge-density polyelectrolytes and interactions between polyelectrolyte-coated surfaces," J. Colloid Interface Sci. 205(1), 77-88.

Ruehrwein, R. A., and Ward, D. W. (1952). "Mechanism of clay aggregation by polyelectrolytes," Soil Sci. 73(6), 485-492.

Ryösö, K. (2001). "Adding retention aid before filler addition - Retention, water removal, and formation," Paper Technol. 42(8), 52-55.

Ryösö, K., and Manner, H. J. (2001). "Reducing fresh water consumption for the feed of retention aids," Appita J. 54(1), 22-26.

Salmi, J., Österberg, M., and Laine, J. (2007b). "The effect of cationic polyelectrolyte complexes on interactions between cellulose surfaces," Colloids Surf. A 297(1-3), 122-130.

Salmi, J., Österberg, M., Stenius, P., and Laine, J. (2007a). "Surface forces between cellulose surfaces in cationic polyelectrolyte solutions: The effect of polymer molecular weight and charge density," Nordic Pulp Paper Res. J. 22(2), 249-257.

Sandell, L. S., and Luner, P. (1974). "Flocculation of microcrystalline cellulose with cationic ionene polymers," J. Appl. Polymer Sci. 18(7), 2075-2083. 
Sanders, N. D., and Schaefer, J. H. (1994). "Comparison of electrophoretic mobility distributions in synthetic papermaking furnishes with streaming potential and polyelectrolyte titration data," Proc. TAPPI 1994 Papermakers Conf., 629.

Schuster, M. A., Harrington, J. C., Liao, W. P., and Chen, F. (1996). "Method for improving retention and drainage characteristics in alkaline papermaking," U. S. Pat. $5,532,308$.

Shin, J.-H., Han, S. H, Sohn, C., and Ow, S. K. (1998). "Retention aids for papermaking," U. S. Pat. 5,717,046.

Shin, J.-H., Han, S. H, Sohn, C., Ow, S. K., and Mah, S. (1997). "Highly branched cationic polyelectrolytes: Filler flocculation,” TAPPI J. 80(11), 179-185.

Shubin, V., and Linse, P. (1995). "Effect of electrolytes on adsorption of cationic polyacrylamide on silica - Ellipsometric study and theoretical modeling," J. Phys. Chem. 99(4), 1285-1291.

Shulga, A., Widmaier, J., Pefferkorn, E., Champ, S., and Auweter, H. (2003a). "Kinetics of adsorption of polyvinylamine on cellulose fibers I. Adsorption from salt-free solutions," J. Colloid Interface Sci. 258(2), 219-227.

Shulga, A., Widmaier, J., Pefferkorn, E., Champ, S., and Auweter, H. (2003b). "Kinetics of adsorption of polyvinylamine on cellulose fibers II. Adsorption from electrolyte solutions," J. Colloid Interface Sci. 258(2), 228-234.

Sikora, M. D., and Stratton, R. A. (1981). "The shear stability of flocculated colloids," Tappi 64(11), 97-101.

Sivén, S. K., and Manner, H. (2001). "Multicomponent retention systems in twin wire forming," Appita J. 54(5), 523-526.

Smith-Palmer, T., and Pelton, R. (2002). "Flocculation of particles," in: Encyclopedia of Surface and Colloid Science, Vol. 2, 2207-2224.

Smook, G. A. (1992). Handbook for Pulp and Paper Technologists, $2^{\text {nd }}$ Ed., Angus Wilde, Vanvouver,

Solberg, D., and Wågberg, L. (2002). "On the mechanism of GCC filler retention during dewatering - New techniques and initial findings," J. Pulp Paper Sci. 28(6), 183-188.

Solberg, D., and Wågberg, L. (2003a). "On the mechanism of cationic-polyacrylamideinduced flocculation and re-dispersion of a pulp fiber dispersion," Nordic Pulp Paper Res. J. 18(1), 51-55.

Solberg, D., and Wågberg, L. (2003b). "Adsorption and flocculation behavior of cationic polyacrylamide and colloidal silica," Colloids Surf. A 219(1-3), 161-172.

Somasundaran, P., Vasudevan, T. V., and Tjipangandjara, K. F. (1992). "Enhanced flocculation and dispersion of colloidal suspensions thorugh manipulation of polymer conformation," Dispersion Aggregation, Proc. Eng. Found. Conf., Moudgil, B. M., and Somasundaran, P. (eds.), 403-418.

Song, J., Wang, Y., Hubbe, M. A., Rojas, O. J., Sulić, N., and Sezaki, T. (2006). "Charge and the dry-strength performance of polyampholytes. Part 1. Handsheet properties and polymer solution viscosity," J. Pulp Paper Sci. 32(3), 156-162.

Spence, G., Palmateer, D. R., and Yarnell, J. R. (1999). "Retention and drainage in alkaline fine paper," U. S. Pat. 6,077,394.

Stack, K. R., and Dunn, L. A. (1995). "Retention improvement in difficult furnishes," $49^{\text {th }}$ Appita Annual General Conf. Proc., Vol. 1B, Paper 13, 83-90. 
Stratton, R. A. (1983). “Effect of agitation on polymer additives,” Tappi J. 66(3), 141144.

Stratton, R. A., and Miller, C. E. (1993). "The effects of retention aid distribution in the furnish," Nordic Pulp Paper Res. J. 8(1), 15-20.

Strazdins, E. (1974). "Surface chemical aspects of polymer retention," Tappi 57(12), 7680.

Strazdins, E. (1977). “Optimization of the papermaking process by electrophoresis," Tappi 60(7), 113-114.

Ström, G., and Kunnas, A. (1991). "The effect of cationic polymers on the water retention value of various pulps," Nordic Pulp Paper Res. J. 6(1), 12-19.

Swerin, A., Glad-Nordmark, G., and Ödberg, L. (1997). "Adsorption and flocculation in suspensions by two cationic polymers - Simultaneous and sequential addition," $J$. Pulp Paper Sci. 23(8), J389-J393.

Swerin, A., and Ödberg, L. (1997). "Some aspects of retention aids," in: The Fundamentals of Papermaking Materials, Baker, C. F. (ed.), Trans. $11^{\text {th }}$ Fundamental Research Symposium, Cambridge, UK, Pira International, Leatherhead, Surrey, UK, Vol. 1, 265-350.

Swerin, A., Ödberg, L., and Lindström, T. (1990). "Deswelling of hardwood kraft pulp fibers by cationic polymers. The effect on wet pressing and sheet properties," Nordic Pulp Paper Res. J. 5(4), 188-196.

Swerin, A., Ödberg, L., and Wågberg, L. (1996). "An extended model for the estimation of flocculation efficiency factors in multicomponent flocculation systems," Colloids Surf. 113(1-2), 25-38.

Swerin, A., Powell, R. L., and Ödberg, L. (1992). "Linear and nonlinear dynamic viscosity of pulp suspensions," Nordic Pulp Paper Res. J. 7(3), 126-132,143.

Swerin, A., Risinger, G., and Odberg, L. (1997). "Flocculation in suspensions of microcrystalline cellulose by microparticle retention aid systems," J. Pulp Paper Sci. 23(8), J374-J381.

Tam Doo, P. A., Kerekes, R. J., and Pelton, R. H. (1984). "Estimates of maximum hydrodynamic shear stresses on fiber surfaces in papermaking," J. Pulp Paper Sci. 10(7), J80-J88.

Tanaka, H., Luner, P., and Côté, W. (1982). "How retention aids change the distribution of filler in paper," Tappi 65(4), 95-99.

Tanaka, H., and Ödberg, L. (1992). "Transfer of cationic polymers from cellulose fibers to polystyrene latex," J. Colloid Interface Sci. 149(1), 40-48.

Tanaka, H., Swerin, A., and Ödberg, L. (1993). "Transfer of cationic retention aid from fibers to fine particles and cleavage of polymer chains under wet-end papermaking conditions," Tappi J. 76(5), 157-163.

Tanaka, H., Swerin, A., Ödberg, L., and Park, S.-B. (1999). "Competitive adsorption of cationic polyacrylamides with different charge densities onto polystyrene latex, cellulose beads, and cellulose fibers," J. Pulp Paper Sci. 25(8), 283-288.

Tay, C. H. (1980). "Application of polymeric flocculant in newsprint stock systems for fines retention improvement," Tappi 63(6), 63-66.

Tay, S. C. H. (1997). "New enhancers to improve polyethylene oxide retention performance on deinked news-print," TAPPI J. 80(9), 149-156. 
Tomi, D., and Bagster, D. F. (1975). "A model of floc strength under hydrodynamic forces," Chem. Eng. Sci. 30(3), 269-278.

Tripattharanan, T., Hubbe, M.A., Venditti, R.A., and Heitmann, J.A. (2004a). "Effect of idealized flow conditions on retention aid performance. 1. Cationic acrylamide copolymer," Appita J. 57(5), 404-410.

Tripattharanan, T., Hubbe, M. A., Heitmann, J. A., and Venditti, R. A. (2004b). "Effect of idealized flow conditions on retention aid performance. Part 2: Polymer bridging, charged patches, and charge neutralization," Appita J. 57(6), 448-454.

Unbehend, J. E. (1976). "Mechanisms of 'soft' and 'hard' floc formation in dynamic retention measurement," Tappi 59(10), 74-77.

Vader, F. V., and Dekker, H. (1978). "The contribution of polymer bridging to the force of adhesion between solids," Mezhdunar. Kong. Poverkhn.-Akt. Veschestvam, $7^{\text {th }}$, 2(II), 691-699.

van de Steeg, T. G. M., Cohen Stuart, M. A., de Keizer, A., and Bijsterbosch, B. H. (1992). "Polyelectrolyte adsorption: A subtle balance of forces," Langmuir 8(10), 2538-2546.

van de Ven, T. G. M. (1981). "Effects of polymer bridging on selective shear flocculation," J. Colloid Interface Sci. 81(1), 290-291.

van de Ven, T. G. M. (1984). "Theoretical aspects of drainage and retention of small particles on the Fourdrinier," Pulp Paper Can. 85(3), T58-T63.

van de Ven, T. G. M. (1997). "Mechanism of fines and filler retention with PEO/cofactor dual retention aid systems," J. Pulp Paper Sci. 23(9), J447-J451.

van de Ven, T. G. M., and Alince, B. (1996a). "Association-induced polymer bridging: New insights into the retention of fillers with PEO," J. Pulp Paper Sci. 22(7), J257J263.

van de Ven, T. G. M., and Alince, B. (1996b). "Heteroflocculation by asymmetric polymer bridging," J. Colloid Interface Sci. 181(1), 73-78.

van de Ven, T. G. M., and Mason, S. G. (1981). "Comparison of hydrodynamic and colloidal forces in paper machine headboxes," Tappi 64(9), 171-175.

van de Ven, T. G. M., Qasaimeh, M. A., and Paris, J. (2004). "PEO-induced flocculation of fines: Effects of PEO dissolution conditions and shear history," Colloids Surf. A 248, 151-156.

van de Ven, T. G. M., Qasaimeh, M. A., and Paris, J. (2005). "Fines deposition on pulp fibers and fines flocculation in a turbulent-flow loop," Ind. Eng. Chem. Res. 44, 12911295.

van de Ven, T. G. M., Qasaimeh, M. A., Pigeon, C., and Paris, J. (2007). "The effect of calcium ions on the efficiency of polyethylene oxide-cofactor retention aid systems," Colloids Surf. A. 297, 79-83.

Vaughan, C. W. (1996). "A new approach to wet-end drainage, retention, and formation technology," TAPPI J. 79(7), 103-109.

Vaughan, C. W., Adamsky, F. A., and Richardson, P. F. (1998). "Two-component additive for dewatering/retention/formation with improved productivity and runnability of the paper machine," Wochenbl. Papierfabr. 126(10), 458-471.

Verwey, E. J. W., and Overbeek, J. Th. G. (1948). Theory of the Stability of Lyophobic Colloids, Elsevier, New York. 
Voigt, J. E., and Pender, H. (1978), "Method of making paper containing cationic starch and anionic retention aid," U. S. Pat. 4,066,495.

Waech, T. G. (1983). "Improving filler retention by adding filler after retention aid addition," Tappi J. 66(3), 137-139.

Wågberg, L. (2000). "Polyelectrolyte Adsorption onto Cellulose Fibers - A Review," Nordic Pulp Paper Res. J. 15(5), 586-597.

Wågberg, L., and Aselli, I. (1995). "The Action of Cationic Polymers in the Fixation of Dissolved and Colloidal Substances. 2," Colloids Surf. A 104(2-3), 169-184.

Wågberg, L., and Lindström, T. (1987). "Some fundamental aspects of dual retention aid systems," Nordic Pulp Paper Res. J. 2(2), 49-55.

Wågberg, L., and Nygren, I. (1999). "The use of stagnation point adsorption reflectometry to study molecular interactions relevant to papermaking chemistry," Colloids Surf. 159, 3-15.

Wågberg, L., Ödberg, L., Lindström, T., and Aksberg, R. (1988). 'Kinetics of adsorption and ion-exchange reactions during adsorption of cationic polyelectrolytes onto cellulosic fibers," J. Colloid Interface Sci. 123(1), 287-295.

Walles, W. E. (1968). "Role of flocculant molecular weight in the coagulation of suspensions," J. Colloid Interface Sci. 27(4), 797-803.

Wang, F., Kitaoko, T., and Tanaka, H. (2003). "Vinylformamide-based cationic polymers as retention aids in alkaline papermaking," TAPPI J. 2(12), 21-26.

Wang, F., and Tanaka, H. (2000). "Aminated poly- $N$-vinylformamide as modern retention aid of alkaline paper sizing with acid rosin sizes," J. Appl. Polymer Sci. 78(10), 1805-1810.

Wang, X. H. (2002). "Surface and colloid chemistry of papermaking," Encyc. Surface Colloid Sci. 4, 4936-4961.

Wang, Y., Hubbe, M. A., Sezaki, T., Wang, X., Rojas, O. J., and Argyropoulos, D. S. (2006). "The role of polyampholyte charge density on its interactions with cellulose," Nordic Pulp Paper Res. J. 21(5), 158-165.

Winter, L., Wågberg, L., Ödberg, L., and Lindström, T. (1986). "Polyelectrolytes adsorbed on the surface of cellulosic materials," J. Colloid Interface Sci. 111(2), 537543.

Wong Shing, J. B., and Hurlock, J. R. (2000). "Papermaking process utilizing hydrophilic dispersion polymers of dimethylaminoethyl acryulate methyl chloride quaternary and acrylamide as retention and drainage aids," U. S. Pat. 6,059,930.

Wong Shing, J. B., Hurlock, J. R., Maltesh, C., and Nagarajan, R. (1998). "Papermaking process utilizating hydrobhilic dispersion polymers of diallyldimethyl ammonium chloride and acrylamide as retention and drainage aids," U. S. Pat. 6,071,379.

Wong Shing, J. B., Maltesh, C., and Hurlock, J. R. (2002). "Method of increasing retention and drainage in papermaking using high molecular weight water-soluble anionic or nonionic dispersion polymers," U. S. Pat. 6,432,271.

Wong Shing, J. B., Gray, R. T., Zelenev, A. S., and Chen, J. (2003). "Method of improving retention and drainage in a papermaking process using a diallyl-N,Ndisubstituted ammonium halide-acrylamide copolymer and a structurally modified cationic polymer," U. S. Pat. 6,592,718. 
Xiao, H., Pelton, R., and Hamielec, A. (1995a). "Flocculation of polystyrene latex by polyacrylamide-copolyethylene glycol,” J. Colloid Interface Sci. 175, 166-172.

Xiao, H., Pelton, R., and Hamielec, A. (1995b). "The association of aqueous phenolic resin with polyethylene oxide and poly(acrylamide-co-ethylene glycol)," J. Polymer Sci.: Part A: Polymer Chem. 33, 2605-2612.

Xiao, H., Pelton, R., and Hamielec, A. (1996a). "Retention mechanisms for twocomponent systems based on phenolic resins and PEO or new PEO-copolymer retention aids," J. Pulp Paper Sci. 22(12), J475-J485.

Xiao, H., Pelton, R., and Hamielec, A. (1996b). "Novel retention aids for mechanical pulps,” TAPPI J. 79(4), 129-135.

Xiao, H., Gibbons, S., Ovenden, C., and Wiseman, N. (1999). "Clay retention induced by poly(ethylene oxide) with various cofactors," Appita J. 52(2), 114-120.

Xu, H-X., Dai, H.-Q., Gong, M.-R., Yuan, G.-X., and Han, C. (2007). "Promotion effect of poly-diallyldimethylammonium chloride monomer on the performance of CPAM as a retention and drainage aid," China Pulp Paper 26(2), 13-16.

$\mathrm{Xu}, \mathrm{Y}$., and Deng, Y. (1999). "Retention of precipitated calcium carbonate in old corrugated container furnishes," TAPPI J. 82(8), 121-126.

Yeung, A., Gibbs, A., and Pelton, R. H. (1997). "Effect of shear on the strength of polymer-induced flocs," J. Colloid Interface Sci. 196, 113-115.

Yeung, A. K. C., and Pelton, R. H. (1996). "Micromechanics: A new approach to studying the strength and breakup of flocs,'F J. Colloid Interface Sci. 184, 579-585.

Yoon, S. H. (2007). "Analysis on adsorption equilibrium of polyamide-epichlorhydrin in aqueous fibrous suspension by colloid titration," J. Industrial Eng. Chem. 13(3), 345351.

Yoon, D.-H., and Park, J.-M. (2005). "Fibers flocculation and physical property changes of paper depending on cationic polymer addition," Palpu Chongi Gisul 37(1), 10-16.

Yoshigara, T., Murahashi, S., and Tadokoro, H. (1964). "Normal vibrations of polymer molecules of helical conformation. 4. Polyethylene oxide and polyethylene-D4 oxide," J. Chem. Phys. 41(9), 2902-2911.

Zeilinger, H., and Klein, M. (1995). "Modern measuring methods for the Z-directional filler distribution," Wochenbl. Papierfabr. 123(20), 903-910.

Zhang, H., Chen, F., and Hu, H. (2003). "Preparations and application of high molecular weight cationic polyacrylamides," China Pulp Paper 22(4), 15-18. 